\title{
Pricing emission permits in the absence of abatement
}

\begin{abstract}
If emissions are stochastic and firms are unable to control them through abatement, the cap in a permit market may be exceeded, or not be reached. I derive a binary options pricing formula that expresses the permit price as a function of the penalty for noncompliance and the probability of an exceeded cap under the assumption of no abatement. I apply my model to the EU ETS, where the rapid introduction of the market made it difficult for firms to adjust their production technology in time for phase 1 . The model fits the data well, implying that the permit price was at least partly driven by firms hedging against stochastic emissions.
\end{abstract}

Keywords: Emission permit markets, EU ETS, option pricing, climate change, air pollution

JEL codes: G12, Q52, Q53, Q54 


\section{Introduction}

The centerpiece of emissions permit market theory is that firms equate their marginal abatement costs with the permit price. If a firm finds abating an additional unit of emissions to be cheaper than buying a permit, it will make a profit from abating and either buy one fewer or sell one more permit on the market. Conversely, if purchasing a permit is cheaper than marginal abatement, the firm will use the permit market to reach compliance. The result of this arbitrage is that marginal abatement costs of all firms are equal to the permit price at every point in time.

However, a permit market may not clear if emissions are stochastic and there are constraints on abatement, banking and borrowing. The natural lower bound for abatement is zero: No firm is forced to actively increase its emissions in order to use up any surplus permits. Therefore, if business-as-usual (BAU) emissions turn out to be below the cap and no banking into the next compliance period is allowed, some permits will not be used. Any upper bound on the permit price, for example in the form of a penalty for noncompliance, translates to an upper bound for abatement: If BAU emissions turn out to be greater than expected (for example due increased consumer demand) and no borrowing from the next compliance period is allowed, firms abate to the extent where their marginal abatement costs are equal to the penalty. The emissions cap will be exceeded because firms that do not hold enough permits to cover their emissions will choose to pay the penalty rather than engage in abatement.

In theory, firms can always reduce emissions by cutting output, but this may be costlier than paying the penalty. Some industries face obligations to provide a certain level of output. An example is the electricity market where supply has to match (stochastic) consumer demand at all times in order for the grid not to crash, and the transmission system operator has the authority to force particular generators on- or offline to ensure continued grid functionality. 
The price path of emission permits during the 2005-2007 period of European Union Emissions Trading Scheme (EU ETS) has puzzled market participants and economists alike (Figure 1). The price was above $€ 20$ for close to 16 months and even surpassed $€ 30$ before plummeting to about half of this value after the first round of emissions accounting in April 2006 revealed that 2005 emissions were below the number of permits issued for that year. Rather than dropping to zero immediately, the permit price remained at around $€ 15$ for another four months before gradually decreasing to zero by mid 2007. The market did in fact not clear for the first compliance phase, with 189 million permits or about $2.7 \%$ of the overall cap expiring unused at the end of 2007 (no banking of permits into the second phase was allowed) despite a positive permit price during most of the time (Table 1).

Figure 1: Allowance price and trading volume during phase 1 of the EU ETS

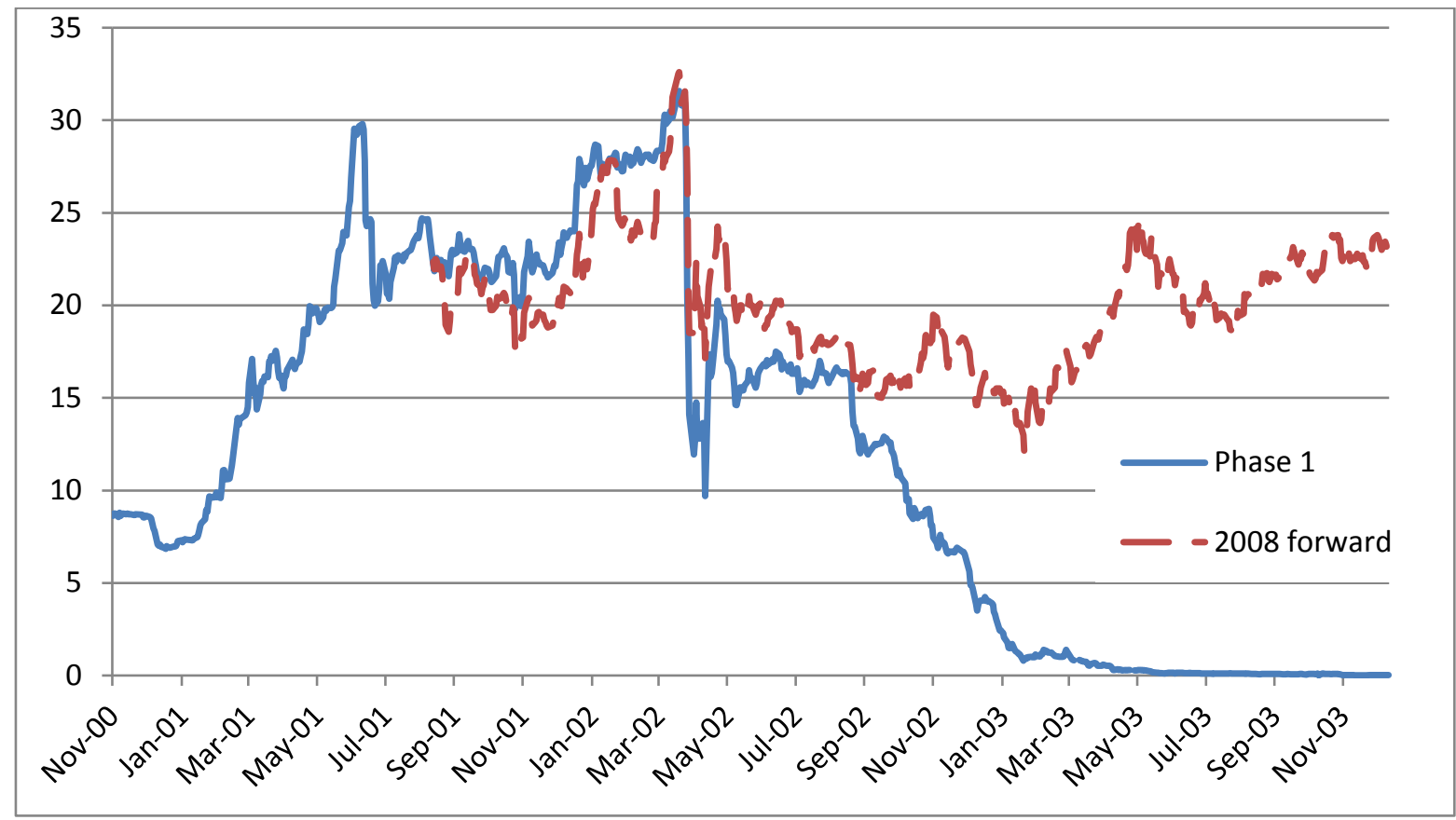

A series of recent studies empirically analyze the first phase of the EU ETS under the assumption of a clearing permit market and continuous equality between the permit price and firms’ marginal abatement costs (Alberola et al., 2008; Bunn and Fezzi, 2008; Hintermann, 2010; Mansanet-Bataller et al., 2007; Rickels et al., 2007). They find limited evidence that the permit price was driven by marginal abatement costs such as fuel prices, economic activity or 
the weather. One possible reason may be that emissions are stochastic, coupled with constraints on abatement. The EU ETS was set up very rapidly, with little more than a year between the initial legislation and the start of the market in January 2005. Because permit banking was not allowed during the first three, only abatement that physically took place by the end of 2007 could affect the first-phase permit price. Considering that planning and installation of new production equipment often takes longer than a few years, most analysts concluded that fuel switching in the power sector (a shift of the generation merit order from coal towards gas) was going to be the predominant method of abatement for phase 1 . On the other hand, electricity generators are typically locked into long-term fuel contracts, ${ }^{1}$ which makes it difficult to engage in fuel switching on a meaningful level.

Table 1: Summary of phase 1 of the EU ETS (Mt=million tons)

\begin{tabular}{lllll}
\hline & 2005 & 2006 & 2007 & Total phase 1 \\
\hline & & & & \\
Price (OTC, time average) & $€ 18.40$ & $€ 18.05$ & $€ 0.72$ & $€ 12.39$ \\
Trading volume & $262 \mathrm{Mt}$ & $817 \mathrm{Mt}$ & $1,364 \mathrm{Mt}$ & $2,443 \mathrm{Mt}$ \\
Allocation (source: CITL) & $2,099 \mathrm{Mt}$ & $2,072 \mathrm{Mt}$ & $2,079 \mathrm{Mt}$ & $6,250 \mathrm{Mt}$ \\
Emissions (source: CITL) & $2,010 \mathrm{Mt}$ & $2,031 \mathrm{Mt}$ & $2,041 \mathrm{Mt}$ & $6,081 \mathrm{Mt}$ \\
Surplus (volume) & $89 \mathrm{Mt}$ & $41 \mathrm{Mt}$ & $39 \mathrm{Mt}$ & $168 \mathrm{Mt}$ \\
Surplus (\%) & $4.22 \%$ & $1.98 \%$ & $1.85 \%$ & $2.69 \%$ \\
\hline a: OTC and exchange trading for phases 1 and 2, but excluding bilateral trades (source: Point Carbon)
\end{tabular}

In this paper set up a model in which firms are unable to control their emissions and buy permits in order to hedge against the possibility of having to pay a penalty. The permit price thus becomes a binary option that is a function of the probability that the emissions cap is exceeded and the penalty for noncompliance, but not of marginal abatement costs. I compute daily emissions based on daily generation of electricity from fossil fuels and use market data from the first phase of the EU ETS to estimate a set of free parameters. The parameter

\footnotetext{
${ }^{1}$ These fuel contracts are often made for gate delivery in the form of take-or-pay, which makes it almost impossible to re-sell the fuel on the market. Because of limited storage capacity, generators are forced to use this fuel by bidding above (current) marginal costs.
} 
estimates are highly significant and make economic sense, and the model fits the data well, especially when allowing for an updating of expectations at the time of the permit price crash.

Previous papers have addressed the issue of stochastic emissions and constraints on abatement (Chesney and Taschini, 2008). However, the stochastic equilibrium models derived in these studies are too complex to be directly applied to data. The main contribution of my paper is therefore empirical. To my knowledge, it is the first to account for the possibility of a non-clearing permit market while allowing for a direct application of the model to market data. In addition, I make use of an extremely detailed dataset about electricity consumption and precipitation across Europe that has not been employed in the empirical literature before.

My model represents a polar case where abatement is constrained to zero and the market is only influenced by expectations about aggregate stochastic emissions and the penalty of noncompliance. The other extreme of the spectrum is defined by the textbook situation where firms have full control over their emissions, and therefore the permit price is exclusively driven by marginal abatement costs. For phase 1 of the EU ETS, the reality is likely to be found somewhere in between: Some abatement probably took place (Ellerman and Buchner, 2008), but the empirical evidence suggests that the permit price was not strongly related to marginal abatement costs. In fact, I find that a large portion of the permit price variation during phase 1 of the EU ETS can be explained without relying on abatement cost drivers at all. This has implications for efficiency, because the equality between marginal abatement costs and the permit price are a prerequisite for achieving an emissions cap at least cost.

Section 2 gives some background about the EU ETS and the relevant literature. In Section 3 I derive an options pricing formula for EU ETS allowances as a function of emissions, the cap, the penalty for noncompliance and a set of free parameters. This formula contains the mean and variance of expected future emissions, which I derive in Section 4 as a function of exogenous stochastic processes. Section 5 presents regression results for the 
parameters of underlying processes and the free parameters in the options pricing formula, and section 6 concludes.

\section{Background}

\subsection{The European Union Emissions Trading Scheme (EU ETS)}

The EU ETS is the world's largest emissions permit market to date and covers the EU's carbon dioxide $\left(\mathrm{CO}_{2}\right)$ emissions from six industrial sectors (Figure 2), among which power \& heat accounts for about $72 \%$ of total emissions. ${ }^{2}$

Figure 2: Emissions by sector (Source: CITL, 2006 data)

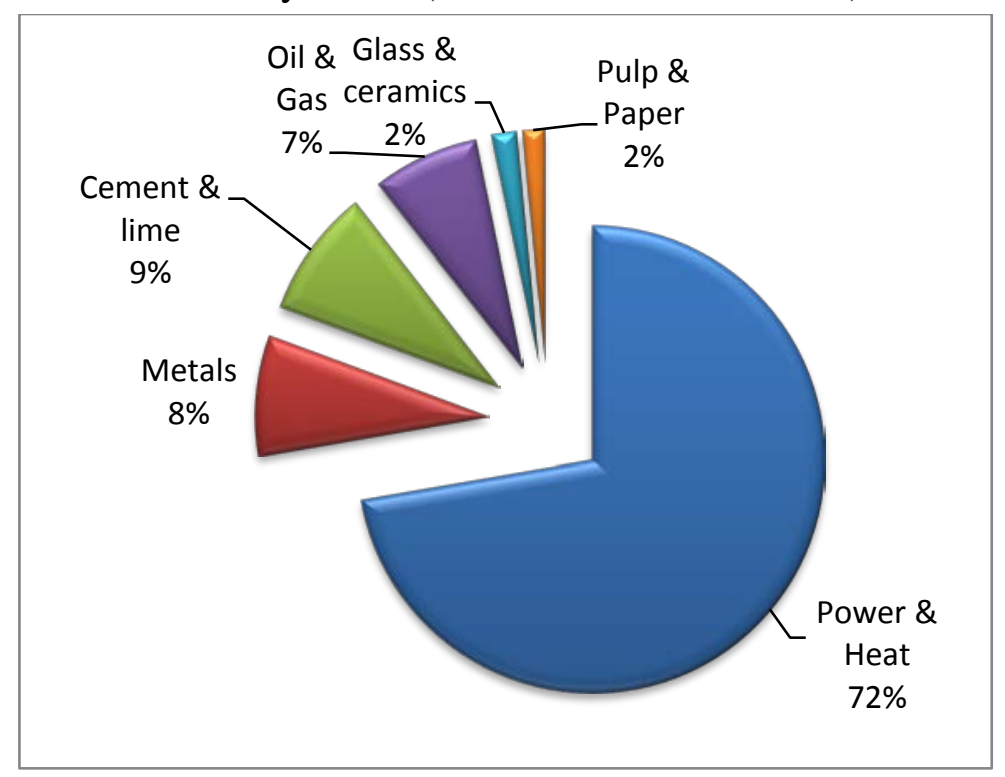

The EU ETS is organized into distinct multiyear periods called “phases” that are subject to different rules and emission caps. The first phase spanned the years 2005-2007 and was considered a pilot run for phase 2, which coincides with the Kyoto compliance period of 2008-

\footnotetext{
${ }^{2}$ The Community Independent Transaction Log (CITL) of the European Commission lists 9 sectors defined by "activity code”, which are: Code 1: Combustion installations with thermal output of >20MW; 2: Mineral oil refineries; 3: Coke ovens; 4: Metal ore roasting or sintering; 5: Production of pig iron and steel; 6: Cement and lime; 7: Glass; 8: Ceramics; 9: Pulp and paper. For the grouping in figure 2, I aggregated codes 3-5 into "metals" and 7-8 into "glass and ceramics". For the other sectors, there is a one-to-one correspondence with activity codes. Within activity code 1, commercial power and heat producers for third parties account for $93 \%$ of emissions, whereas the remaining $7 \%$ come from numerous but relatively small installations involved in the production of on-site power and heat (so-called “autoproducers”).
} 
2012. First-phase allowances (one-time rights to emit one ton of $\mathrm{CO}_{2}$, denoted as EUA) could not be banked into the second phase and lost their value if unused for compliance. ${ }^{3}$ About 12,000 individual installations received a total of 2.1 billion emission allowances annually, mostly at no cost. For a more detailed discussion of the market setup, see Kruger and Pizer (2004) and the PEW White Paper (2005).

Firms received allowances allocated mostly for, based on estimates of historic emissions. Firms can trade allowances freely within the EU, either bilaterally, through brokers (over-thecounter or OTC trades) or on one of six exchanges. By April 30, they have to report their emissions and surrender permits corresponding to their emissions in the previous calendar year. For every ton of emitted $\mathrm{CO}_{2}$ for which they do not surrender an allowance, firms have to pay a penalty (€40 in phase 1 and $€ 100$ in phase 2 ) as well as surrender the missing allowance in the following year. Because firms receive annual allowances in March they can effectively bank and borrow across time within a market phase, which implies that the penalty of noncompliance will only be applied at the end of a phase. Since allowance allocation exceeded emissions for phase 1 , the penalty has not been applied to date.

Because of the lack of historic emissions data in Europe, many countries relied on firms' emissions forecasts when determining permit allocation, which introduced rather obvious incentive problems. There seems to be a general agreement among analysts that the first round of emissions accounting in April 2006 revealed lower-than-expected emissions, indicating that the cap was more generous than previously believed. The downward adjustment of market participants' expectations about aggregate emissions for phase 1 caused the allowance price to lose half of its value within a day. What is less evident than the reasons for the crash is why the

\footnotetext{
${ }^{3}$ Banking is allowed between the second and later phases.
} 
price was so high in the first place, ${ }^{4}$ and why it did not crash to zero but remained in a range of $€ 15$ for several months afterwards.

Another feature of the EU ETS that may be important in the context of this paper is the process for second-phase allocation, which took first-phase emissions into account. The European Commission urged member countries not to engage in such “allocation updating”, but most of them based their national allocation plans for phase 2 on verified 2005 emissions anyway. ${ }^{5}$ Basing future allocation on current emissions creates a strong disincentive to abate, because every unit of abatement comes at a cost not only in the current period but also causes a reduction in future free allocation (Boehringer and Lange, 2005). As a result, it is possible or even likely that firms stuck to their existing fuel contracts and merit order even if they had been able to engage in fuel switching (or any other form of abatement).

\subsection{Literature}

There is a large theoretical literature in environmental economics about permit trading, starting with the seminal work of Montgomery (1972) and Tietenberg (1985). Later contributions extended the analysis to incorporate banking and borrowing of permits (Cronshaw and Brown-Kruse, 1996; Leiby and Rubin, 2001; Rubin, 1996) and to address uncertainty (Newell et al., 2005; Schennach, 2000; Zhao, 2003). All of these studies show that it is optimal from a social and a firm perspective to equate marginal abatement costs to the permit price, and that this will lead to the achievement of an emissions reduction target at least cost.

\footnotetext{
${ }^{4}$ If all firms with an allowance surplus brought them to the market, the price would incorporate information about aggregate BAU emissions and the resulting necessary abatement levels. The fact that the allowance price was positive during much of the first phase, in spite of an over-allocation indicates that the allowance price did not reflect all relevant information.

${ }^{5}$ Although obviously problematic from a permit market point of, one has to consider the fact that most EU member countries had very little information about $\mathrm{CO}_{2}$ emissions. Given a grandfathering allocation method, it was very difficult for most countries to completely disregard the new information gained during the first year of the market.
} 
Empirical studies about price determination in the EU ETS are inconclusive about whether observed allowance prices are indeed determined by marginal abatement costs. In one of the first empirical analyses of the market, Mansanet-Bataller et al. (2007) regress allowance price changes on changes in fuel prices and extreme weather conditions for the first year of the market (2005) and find some statistically significant coefficients with the expected sign, but the explanatory power of the model was quite weak. The most significant exogenous variable turned out to be the oil price, which is not an abatement-related measure (very little electricity is produced using oil in the EU, and neither the transportation nor the residential sectors are covered by the market), and the fuel switch price from coal to gas was not significant. Rickels et al. (2007) extend the analysis to 2006 and find some correspondence between allowance prices, fuel prices and European weather before the April 2006 price crash, but virtually none for the period afterwards. They also checked for cointegration between allowance and fuel prices, which would be evidence of a systematic relationship, but found none. In contrast, Bunn and Fezzi (2008) did find a cointegrating relationship between prices for allowances, gas and electricity, but the relationship between gas and allowance prices was weak and possibly due to the fact that both prices are related to electricity prices.

Hintermann (2010) derives a market model that expresses allowance price changes as a function of market fundamentals related to the overall cap and abatement by fuel switching and estimates the resulting regression using market data through mid 2007. He finds that before the price crash, there was no correlation between abatement-related fundamentals and the allowance price. The results for the period after the April 2006 price crash are somewhat more supportive of the idea of fuel switching, but fuel prices explained a minor share of the allowance price variation even in the best-matching specification of a large number of specifications. 
Another strand of literature has looked at the issue from a mathematical finance perspective, focusing on the dynamics of allowance prices and methods to hedge against emissions-related risk. Kosobud et al. (2005) applied financial tools to the analysis of $\mathrm{SO}_{2}$ permits in the US Acid Rain program, and Paolella and Taschini (2008) examine the same market as well as the EU ETS. They find that allowance price returns are fat-tailed and thus are best modeled using models that take this property into account. However, they use a pure time series approach and do not aim to identify exogenous price drivers. In a similar approach, Benz and Trueck (2009) focus on the properties of short-term allowance price returns, and propose the use of Markov-switching models and time-varying volatility measures to describe the observed prices.

Chesney and Taschini (2008) develop a theoretical model that incorporates asymmetric information in the sense that firms have more complete information about their own emissions than about those of other firms in the market. Under the assumption that firms were not able to abate emissions before the end of 2007, they show that allowances are financial options and simulate allowance prices that for some parameter values show a bubble-like price path similar to that observed for phase-1 EUAs.

Seifert et al (2008) derive a stochastic equilibrium permit price model and analyze the resulting EUA price dynamics. They prove that discounted allowance prices are martingales, meaning that they do not follow a seasonal pattern but immediately incorporate all relevant market information. The authors argue that the allowance price in their model will never reach zero before the end of the period because the stochastic nature of prices, emissions and abatement ensures a positive probability that the cap turns out to be binding and the penalty for noncompliance has to be paid, a result which also features in my model.

Carmona et al. (2009) also develop a model in which allowance prices are driven by the probability of the cap to be exceeded, the cash part of the penalty for noncompliance (but not 
the second-phase allowances that also form part of the penalty) and fuel prices. They conclude with a numerical analysis based on a simplified model version where they use market data to calibrate emission and fuel price processes, although their setup does not allow them to incorporate daily data to update firms' expectations about future emissions. They find that their proxy for marginal abatement costs, namely the current cost to abate one ton of $\mathrm{CO}_{2}$ by fuel switching, is not highly correlated with the allowance price, supporting my assumption about the irrelevance of abatement during phase 1 of the EU ETS.

\section{Model}

Let $P_{t}$ be the closing price for an allowance on day $t$, with the index $t=(1,2, \ldots, T)$ starting on January 1, 2005 and ending on December 31, 2007. $\mathrm{CO}_{2}$ emissions on day $t$ are represented by $g_{t}$. Let $G_{1}^{t} \equiv \sum_{k=1}^{t} g_{k}$ denote cumulative realized emissions (observed with certainty) and $G_{t}^{T} \equiv \sum_{k=t+1}^{T} g_{k}$ cumulative future emissions until the end of the market (stochastic). Furthermore, let $\bar{P}$ refer to the penalty for noncompliance and $S_{0}$ to the total emissions cap over the entire market period imposed by the regulator. Finally, it will be useful to define $S_{t}=S_{0}-G_{1}^{t}$ to be the "remaining cap" until the end of the market.

The purchase of an allowance gives the bearer the option to use it for compliance at the end of the period or to sell it. However, if the cap turns out to be not binding, the bearer can retire the allowance. This makes an allowance a financial option, specifically a binary call option, also called a cash-or-nothing option, a point also made by Chesney and Taschini (2008). At time $T$ the payoff from holding an allowance is:

$$
P_{T}=\left\{\begin{array}{lll}
0 & \text { if } & S_{T}>0 \\
\bar{P} & \text { if } & S_{T} \leq 0
\end{array}\right.
$$


The penalty of noncompliance $\bar{P}$ consists of a cash penalty of $€ 40$ plus the cost of buying an additional permit for the second phase. Let $P_{t}^{I I}$ represent the price of the December-2008 forward contract for an allowance at time $t$. The penalty at time $T$ can then be written as ${ }^{6}$

$$
\bar{P}=€ 40+P_{T}^{I I}
$$

At $t<T$ it is not known whether the cap will be exceeded, provided that it has not been exceeded already. The expected payoff from holding an allowance at time $T$ is

$$
\begin{aligned}
& E_{t}\left[P_{T} \mid S_{t}>0\right]=E_{t}[\bar{P}] \cdot \int_{S_{t}}^{\infty} \zeta_{t}\left(G_{t}^{T}\right) d G_{t}^{T} \\
& E_{t}\left[P_{T} \mid S_{t} \leq 0\right]=E_{t}[\bar{P}]
\end{aligned}
$$

where $\zeta_{t}\left(G_{t}^{T}\right)$ denotes the probability density function over cumulative future $\mathrm{CO}_{2}$ emissions $G_{t}^{T}$ and $E_{t}[\cdot]$ stands for the expectation taken using all information available at time t. The time subscript on the expectation about the penalty results from changing expectations about the second-phase price, which is relevant for the non-cash part of the penalty.

I specify emissions as a linear combination of normally distributed processes (see Section 4), which means that they are normally distributed as well. Options pricing formulae are usually based on log-normally distributed underlying assets, reflecting the idea that total returns are the multiplication of single-period returns. Cumulative emissions, however, are additive rather than multiplicative, and it is therefore appropriate to model them using a normal distribution. $^{7}$ Let $\mu_{t}$ and $s_{t}$ denote the mean and standard deviation of stochastic cumulative

\footnotetext{
${ }^{6}$ The cash penalty has to be paid after the end of the first phase, whereas the additional permits will have to be surrendered in 2009 together with permits for the calendar year 2008. Because permits can be banked and borrowed within a phase, I abstract from the difference in timing of the two penalty components.

${ }^{7}$ In theory, the choice of a normal distribution requires a truncation at zero necessary since negative emissions are not defined. But because $\mathrm{CO}_{2}$ emissions in the EU are many standard deviations away from zero, the correction implied by the truncation is extremely small, such that for the remainder of this paper I will neglect the truncation issue.
} 
future emissions $G_{t}^{T}$. Its standardized form $Q_{t} \equiv\left(G_{t}^{T}-\mu_{t}\right) / s_{t}$ has a standard normal distribution by construction. Let $\varphi(\cdot)$ and $\Phi(\cdot)$ be the probability density function and cumulative probability density function of the standard normal distribution, respectively. I now convert the integral in (3) into an integral over $Q_{t}$ :

$$
\begin{aligned}
E_{t}\left[P_{T} \mid S_{t}>0\right] & =E_{t}[\bar{P}] \cdot \int_{\left(S_{t}-\mu_{t}\right) / s_{t}}^{\infty} \phi\left(Q_{t}\right) d Q_{t} \\
& =\left(€ 40+E_{t}\left[P_{T}^{I I}\right]\right) \cdot \Phi\left(\frac{\mu_{t}-S_{t}}{s_{t}}\right)
\end{aligned}
$$

Arbitrage considerations dictate that the price at time t be equal to the expected price at $T$, discounted by the risk-free rate of interest $r .{ }^{8}$ Due to arbitrage considerations, the expected second-phase price at time $T$ has to be the current forward price, scaled by the rate of interest, such that $E_{t}\left[P_{T}^{I I}\right]=e^{r(T-t)} P_{t}^{I I}$. Thus, the discounted expected allowance price at time $T$ is ${ }^{9}$

$$
\begin{aligned}
& e^{-r(T-t)} E_{t}\left[P_{T} \mid S_{t}>0\right]=\left(40 e^{-r(T-t)}+P_{t}^{I I}\right) \cdot \Phi\left(\frac{\mu_{t}-S_{t}}{S_{t}}\right) \\
& e^{-r(T-t)} E_{t}\left[P_{T} \mid S_{t} \leq 0\right]=40 e^{-r(T-t)}+P_{t}^{I I}
\end{aligned}
$$

The first parenthesis in (5) is the discounted total penalty for noncompliance per ton of uncovered emissions consisting of the cash penalty and a second-phase allowance. The term $\Phi(\cdot)$ represents the probability that the cap is exceeded, which is unity for the second line.

\footnotetext{
${ }^{8}$ Real-world markets are typically not risk-neutral, but option prices based on risk neutrality nevertheless yield the correct (meaning no-arbitrage) solution for traded assets (Hull, 2002). In the case of emissions, the risk may be spanned by electricity future contracts, weather options and derivatives based on emissions-related indicators such as temperature in rivers close to nuclear power plants (if water temperatures are too high to cool the plants, nuclear generation is switched off, as has happened in Sweden in the Summer of 2005). In any case, the price of market risk can never be determined with a sufficient degree of confidence in order to make its inclusion in an empirical pricing formula worthwhile, due to measurement and identification issues (e.g. a greater market fundamental and a higher price of risk have the same effect on the price).

${ }^{9}$ For a fully rigorous exposition that leads to the same result, see Chesney and Taschini (2008) and Carmona (2009). The latter also prove that the permit price is indeed a martingale, a property which is assumed but not formally derived here.
} 
Equation (5) is a binary options formula for the allowance price, with the underlying asset being normally distributed cumulative future emissions. What remains to be determined in order to evaluate (5) are past emissions (to compute $S_{t}$ ) and the mean and standard deviation of cumulative future emissions, $\mu_{t}$ and $s_{t}$. Daily emissions are not actually observed, but have to be derived from underlying processes and ultimately estimated using market data. This is the subject of the following section.

\section{Mean and standard deviation of future emissions}

\subsection{Processes underlying $\mathrm{CO}_{2}$ emissions}

There exist no data about daily $\mathrm{CO}_{2}$ emissions, but for the power and heat sector there is something that can serve as a substitute: Daily electricity consumption.

Electricity is special in the sense that demand has to be met with a matching supply at all times in order for the grid not to collapse. I assume that the short-term price elasticity of electricity consumption is zero, such that electricity supply is equal to demand, which in turn is a function of exogenous processes such as the weather and overall economic activity. ${ }^{10}$

Because only generation from fossil fuels contributes to $\mathrm{CO}_{2}$ emissions, I have to adjust total consumption by the availability of “clean” (i.e. non-CO $\mathrm{CO}_{2}$-emitting) sources of electricity, mainly hydroelectric and nuclear power. ${ }^{11}$

\footnotetext{
${ }^{10}$ In the long run, consumers will react to higher electricity prices by changing their consumption habits and appliance portfolio, such that electricity demand is also a function of the electricity price. But regardless of the time horizon and the associated energy efficiency of households and industry, exogenous shocks will always drive short-term electricity consumption.

${ }^{11}$ Although wind generation has increased rapidly during the past few years, it still accounts for a relatively small fraction of total power production.
} 
Let $c_{t}$ represent overall electricity consumption; $c_{t}^{c}$ consumption of conventional fossilfueled generation; $n_{t}$ nuclear power generation (all in Giga-Watt-hours (GWh) per day); and $h_{t}$ rainfall in the EU in millimeters (mm) per day. Demand for conventional generation is

$$
c_{t}^{c}=c_{t}-\eta h_{t}-n_{t}
$$

where $\eta$ is a fixed coefficient translating precipitation into hydroelectric power. ${ }^{12} \mathrm{I}$ compute $\eta$ by dividing the EU's total hydro generation in 1990-2005 of 4,852,000 GWh by cumulative weighted precipitation over the same period of 9,775 mm, using installed hydroelectric capacity per country as weights. This results in a conversion factor of $\eta=496.4$ $\mathrm{GWh} / \mathrm{mm}$.

Nuclear generation is “flat”, i.e. power plants are not ramped up and down on a daily or even seasonal basis but provide constant output. In the EU, 12 member countries have nuclear power plants. ${ }^{13}$ Their combined average generation in the years 2003-2005 was 2,679 GWh per day, which I will use as a measure for $n_{t}=n \forall t$.

The emission intensity of the marginal generator varies over the dispatch order (the sequence according to which generators come online, usually based on least cost). The correct measure for $\mathrm{CO}_{2}$-emissions in Europe's power \& heat sector is

$$
g_{t}=\int_{0}^{c_{t}^{c}} \Psi_{t}(y) d y
$$

\footnotetext{
${ }^{12}$ Since precipitation can be stored to some extent, either in reservoirs or as snow in the mountains, there is no immediate relationship between precipitation and hydro generation on any given day. On the long run, however, all hydro generation is ultimately due to precipitation, and even if rainfall today may not translate into more generation today, it nevertheless reduces expected conventional generation needed to satisfy consumer electricity demand until the end of the phase.

${ }^{13}$ These are Belgium, Czech Republic, Germany, Spain, Finland, France, Hungary, Netherlands, Slovakia, Slovenia, Sweden and UK.
} 
where $\Psi_{t}\left(c_{t}^{c}\right)$ is a function transforming conventional thermal power generation into emissions. To compute the integral in (7) I would need to know the dispatch order for each day, as well as the marginal emission intensity of all generators involved, information which is not available. Instead, I approximate the emission intensity of all generators that are not continuously running by a linear function. This allows me to express (7) as

$$
\begin{aligned}
& g_{t} \approx k+\gamma \cdot c_{t}^{c} \\
& k \equiv g^{\min }-\gamma \cdot \min \left(c_{t}^{c}\right)
\end{aligned}
$$

The parameter $\gamma$ represents the average emission intensity of fossil-fueled electricity generation beyond minimum consumption $\min \left(c_{t}^{c}\right)$. For the period under consideration I treat $\gamma$ as fixed. The constant $k$ captures the difference between $\mathrm{CO}_{2}$ emissions associated with minimum thermal generation $g^{\text {min }}$ and the (theoretical) emissions if the emission intensity $\gamma$ were applicable to infra-marginal generation as well. ${ }^{14}$ Combining (6) and (8), emissions are a function of a set of parameters and the two stochastic exogenous processes $c_{t}$ and $h_{t}$ :

$$
g_{t}=k+\gamma \cdot\left(c_{t}-\eta h_{t}-n\right)
$$

At time $\mathrm{t}$, the mean of future $\mathrm{CO}_{2}$ emissions is defined by

$$
\begin{aligned}
\mu_{t}=E_{t}\left[G_{t}^{T}\right] & =E_{t}\left[\sum_{k=t+1}^{T} k+\gamma \cdot\left(c_{k}-\eta h_{k}-n\right)\right] \\
& =(T-t) k+\gamma \cdot \sum_{k=t+1}^{T}\left(E_{t}\left[c_{k}\right]-\eta E_{t}\left[h_{k}\right]-n\right)
\end{aligned}
$$

\footnotetext{
${ }^{14}$ The average emission intensity of inframarginal conventional generation can be greater or smaller than the emission intensity of marginal generation. For example, if inframarginal generation stems largely from lignite or anthracite coal power plants, then $k>0$ because these generators have a greater emission intensity than the marginal conventional generators which are predominantly hard coal and gas generators. On the other hand, if inframarginal generation contains a large share of combined cycle gas turbines (CCGTs), then $k<0$. In the $\mathrm{EU}, k>0$ is more likely given the significant fraction of lignite generation in Germany and the new EU member countries from Eastern Europe.
} 
The variance (for a derivation see Appendix) is

$$
\begin{aligned}
S_{t}^{2}=\operatorname{Var}_{t}\left[G_{t}^{T}\right]= & \sum_{k=t+1}^{T} \operatorname{Var}_{t}\left[g_{k}\right]+2 \sum_{k=t+1}^{T} \sum_{u=k+1}^{T} \operatorname{Cov}_{t}\left[g_{k}, g_{u}\right] \\
= & \gamma^{2} \sum_{k=t+1}^{T}\left(\operatorname{Var}_{t}\left[c_{k}\right]-2 \eta \operatorname{Cov}_{t}\left[c_{k}, h_{k}\right]+\eta^{2} \operatorname{Var}_{t}\left[h_{k}\right]\right) \\
& +2 \gamma^{2} \sum_{k=t+1}^{T} \sum_{u=k+1}^{T}\left(\operatorname{Cov}_{t}\left[c_{k}, c_{u}\right]+\eta^{2} \operatorname{Cov}_{t}\left[h_{k}, h_{u}\right]-\eta \operatorname{Cov}_{t}\left[c_{k}, h_{u}\right]-\eta \operatorname{Cov}_{t}\left[h_{k}, c_{u}\right]\right)
\end{aligned}
$$

Both expressions are functions of the constants $n$ and $\eta$ (which I treat as fixed), the parameters $k$ and $\gamma$, and the mean, variance and covariance of electricity consumption and precipitation, the derivation of which is the subject of the next subsection.

\subsection{Properties of the stochastic processes $c_{t}$ and $h_{t}$}

For the analysis of the stochastic processes that describe electricity demand and precipitation, I will draw extensively from a paper by Alaton et al. (2002). Although they focus on pricing a weather option over heating-degree days, their analysis can also be applied to electricity demand and precipitation because both are exogenously driven stochastic processes that contain deterministic annual fluctuation and long-term trends. The contribution of my paper is not the derivation of the property of such processes, but the application of these methods to $\mathrm{CO}_{2}$ allowance pricing.

I model both electricity consumption and precipitation as diffusion processes consisting of a deterministic mean and a stochastic part, and which exhibit mean-reversion. For mathematical tractability, I include the stochastic element in the form of a generalized Wiener process. Combining the processes in the index $x=c, h$, they can be described as

$$
d x_{t}=\left[\frac{d x_{t}^{m}}{d t}+a_{x} \cdot\left(x_{t}^{m}-x_{t}\right)\right] d t+\sigma_{i(t)}^{x} d W_{t}^{x} \quad x=c, h
$$


This is known as an Ornstein-Uhlenbeck (OU) process with a non-zero mean $x_{t}^{m}$ that changes over time, and time-varying volatility. The term in brackets represents the drift, followed by the diffusion term defined by the standard Wiener process $d W_{t}^{x}$ multiplied by the volatility. The mean reversion parameter $a_{x}$ measures the speed at which the processes revert back to their long-term mean. Lastly, the index $i(t)$ labels the calendar month to which the time index $t$ refers. I constrain the volatility to be constant within each calendar month, but allow it to differ across months, such that $i(t) \in(1, \ldots, 12)$. For example, if day $t$ belongs to January of any year, then $i(t)=1$.

The standard form of the OU-process can be derived simply by setting $d x_{t}^{m} / d t=0$ and $\sigma_{i(t)}^{x}=\sigma^{x}$ (note that the volatility remains deterministic in spite of its time subscript). At $s \leq t$, the solution for the stochastic differential equations in (12) is

$$
x_{t}=\left(x_{s}-x_{s}^{m}\right) \cdot e^{-a_{x}(t-s)}+x_{t}^{m}+\int_{s}^{t} e^{-a_{x}(t-\tau)} \sigma_{i(\tau)}^{x} d W_{\tau}^{x}
$$

The first term on the RHS is the deviation of actual consumption/precipitation at the present time s from its mean. As time goes on, the impact of this deviation will diminish due to the mean-reversion property of both processes, measured by the exponent. If one of the processes is at its average at time $\mathrm{s}$, or if $t>>s$, then the first term will drop out, and the expectation at time t simply becomes $x_{t}^{m}$.

In my empirical approach, I specify the long-term mean of electricity consumption and precipitation at time $t$ as

$$
x_{t}^{m}=\beta_{0}^{x}+\beta_{1}^{x} \cdot t+\beta_{2}^{x} \cdot \sin \left[2 \pi t / 365+\omega^{x}\right]+D^{x} \cdot W D_{t}
$$


The parameters $\beta_{0}^{x}$ and $\beta_{1}^{x}$ describe the level and trend of the process $x$, respectively, whereas $\beta_{2}^{x}$ describes the amplitudes of the respective sine wave. The phase angle $\omega^{x}$ shifts the oscillation of the two processes to their correct position. Lastly, the vector of coefficients $D^{x}$ accounts for differences across different weekdays, with $W D_{t}$ being a vector of weekday dummies (this only applies to electricity consumption, as there is no reason to believe that precipitation follows a particular weekday pattern).

Using (13), we can compute the mean and variance of future electricity demand and precipitation. The expectation of the level of the process at time $t$, taken on day $s$, depends on the deviation of the current level from its long-term mean, as well as the expected long-term at time $t$ :

$$
E_{s}\left[x_{t}\right]=\left[x_{s}-x_{s}^{m}\right] \cdot e^{-a_{x}(t-s)}+x_{t}^{m}
$$

Since the diffusion term in (12) is unaffected by the presence of a deterministic timevarying mean, the variance is that of a regular OU-process and is derived by applying Itô's integral of a deterministic integrand (for a general treatment, see Shreve (2004)):

$$
\operatorname{Var}_{s}\left[x_{t}\right]=E_{s}\left[\left(x_{t}-E_{s}\left[x_{t}\right]\right)^{2}\right]=\int_{s}^{t} e^{-2 a_{x}(t-y)}\left(\sigma_{i(y)}^{x}\right)^{2} d y
$$

If the volatility does not change between $s$ and time $t$, (16) can be solved for

$$
\operatorname{Var}_{s}\left[x_{t}\right]=\frac{\left(\sigma_{i(t)}^{x}\right)^{2}}{2 a_{x}}\left(1-e^{2 a_{x}(t-s)}\right)
$$

If the variance changes between $s$ and $t$, the expression becomes more complicated. I will denote the first day of each month as $t_{i}^{\min }=\min \{t: i(t)=i\}$. I show in the Appendix that for $x=c, h$ and $i(s) \leq i(t)$, the general expression for the variance is 


$$
\operatorname{Var}_{s}\left[x_{t}\right]=\frac{1}{2 a_{x}}\left\{\sum_{k=i(s)}^{i(t)-1}\left[\left(\sigma_{k}^{x}\right)^{2}-\left(\sigma_{k+1}^{x}\right)^{2}\right] e^{-2 a_{x}\left(t-t_{k+1}^{\min }\right)}+\left(\sigma_{i(t)}^{x}\right)^{2}-e^{-2 a_{x}(t-s)}\left(\sigma_{i(s)}^{x}\right)^{2}\right\}
$$

If the volatility is constant across different calendar months, (18) reduces to (17).

Lastly, the covariance between electricity consumption and precipitation on days $t$ and $u$ for $s \leq t \leq u$ is defined by (see Appendix):

$$
\begin{aligned}
& \operatorname{Cov}_{s}\left[x_{t}, x_{u}\right]=e^{-a_{x}(u-t)} \cdot \operatorname{Var}_{s}\left[x_{t}\right] \\
& \operatorname{Cov}_{s}\left[c_{t}, h_{u}\right]=e^{-a_{h}(u-t)} \cdot \operatorname{Cov}_{s}\left[c_{t}, h_{t}\right] \\
& \operatorname{Cov}_{s}\left[h_{t}, c_{u}\right]=e^{-a_{c}(u-t)} \cdot \operatorname{Cov}_{s}\left[c_{t}, h_{t}\right]
\end{aligned}
$$

There is no reason to believe that consumption of electricity and precipitation on the same day should be systematically related, and the data confirm this. I therefore set $\operatorname{Cov}_{s}\left[c_{t}, h_{t}\right]=$ $\operatorname{Cov}_{s}\left[c_{t}, h_{u}\right]=\operatorname{Cov}_{s}\left[h_{t}, c_{u}\right]=0$ in eq. (11). Expressions (15) and (18)-(19) can now be substituted into (10) and (11), which in turn have to be substituted into (5).

\section{Estimation}

Estimation proceeds in two steps: First, I estimate the parameters $\beta_{0}^{x}, \beta_{1}^{x}, \beta_{2}^{x}, \omega^{x}, D^{c}, a_{x}$ and $\sigma_{1}^{x}, \ldots, \sigma_{12}^{x}$, using data available through 2005, or through 2007 where necessary (see below). Second, I estimate the remaining parameters in $\mu_{t}$ and $S_{t}$ in the allowance pricing formula (5) using data starting in 2006, treating the first-step estimates as given. 


\section{1.) Data}

Allowance prices: Over-the-counter (OTC) closing allowance prices from Point Carbon.

Electricity consumption: Daily data about electricity consumption is available from the Union for the Coordination of Transmission of Electricity (UCTE) for continental European countries, ${ }^{15}$ including all EU member countries except for the Nordic countries, the UK, Ireland, the Baltic States, Malta and Cyprus. Electricity consumption on the third Wednesday of each month is available starting in 1994 for 9 EU countries, in 1996 for Germany, and in 1999 for another 5 countries. Consumption on the weekend following the third Wednesday of each month is available for the year 2000 only. Starting in 2006, electricity consumption is available on a daily basis for all UCTE countries. To supplement the UCTE data I obtained historic electricity consumption data from the transmission system operators (TSOs) in the UK, Ireland and the Nordic countries. ${ }^{16}$ I exclude Malta, Cyprus and the Baltic States due to lack of data. The 20 countries included in the analysis account for $99 \%$ of total production in the EU25. The EU produces nearly all of the electricity it consumes, with net imports/exports accounting for less than 0.1 percent of overall consumption. I therefore set EU consumption equal to EU generation. In order to accommodate the variation in type and provenance of the data I will carry out the analyses separately for each group of countries for which the available data is of the same type and covers the same time period. The six groups are listed in Table 2, and Figures 3a-f show the available pre-2006 electricity consumption data by group.

\footnotetext{
${ }^{15}$ Available at http://www.entsoe.eu/, last accessed in September 2008.

${ }^{16}$ UK: Daily data since 2001 from the National grid, available at http://www.nationalgrid.com/uk/Electricity/Data/; Ireland: Daily data since 2002 from Eirgrid, available at http://www.eirgrid.com; Denmark: Daily data since 2000 from Energinet, available at http://www.energinet.dk; Finland: Daily data since 2004 from Fingrid, available at http://www.fingrid.fi; Sweden: Daily data since 2000 from Svenska Kraftnät, available at http://www.svk.se/web/Page.aspx?id=5794.
} 
Table 2: Data availability (pre-2006) and installed hydroelectric capacity by country

\begin{tabular}{|c|c|c|c|c|}
\hline \multirow[t]{2}{*}{ Countries } & \multicolumn{3}{|c|}{ Start of data series } & \multirow{2}{*}{$\begin{array}{l}\text { Hydro capacity } \\
\text { in } 2006 \text { (MW) }\end{array}$} \\
\hline & Type & Year & Source $^{\mathrm{a}}$ & \\
\hline \multicolumn{5}{|l|}{ Group 1} \\
\hline Austria & 3rd Wed. & 1994 & UCTE & $11^{\prime} 811$ \\
\hline Belgium & 3rd Wed. & 1994 & UCTE & 1'411 \\
\hline France & 3rd Wed. & 1994 & UCTE & $25^{\prime} 457$ \\
\hline Greece & 3rd Wed. & 1994 & UCTE & 3'133 \\
\hline Italy & 3rd Wed. & 1994 & UCTE & $21^{\prime} 070$ \\
\hline Luxembourg & 3rd Wed. & 1994 & UCTE & 1'128 \\
\hline Netherlands & 3rd Wed. & 1994 & UCTE & 37 \\
\hline Portugal & 3rd Wed. & 1994 & UCTE & 4'948 \\
\hline Spain & 3rd Wed. & 1994 & UCTE & $20 ' 714$ \\
\hline \multicolumn{5}{|l|}{ Group 2} \\
\hline Germany & 3rd Wed. & 1996 & UCTE & 9'100 \\
\hline \multicolumn{5}{|l|}{ Group 3} \\
\hline Czech Republic & 3rd Wed. & 1999 & UCTE & 2'175 \\
\hline Hungary & 3rd Wed. & 1999 & UCTE & 46 \\
\hline Poland & 3rd Wed. & 1999 & UCTE & 2'324 \\
\hline Slovak Republic & 3rd Wed. & 1999 & UCTE & $2^{\prime} 429$ \\
\hline Slovenia & 3rd Wed. & 1999 & UCTE & 873 \\
\hline \multicolumn{5}{|l|}{ Group 4} \\
\hline UK & daily & 2002 & Country TSO & 4'256 \\
\hline Ireland & daily & 2002 & Country TSO & 512 \\
\hline \multicolumn{5}{|l|}{ Group 5} \\
\hline Denmark & daily & 2000 & Country TSO & 10 \\
\hline Sweden & daily & 2000 & Country TSO & $16^{\prime} 180$ \\
\hline \multicolumn{5}{|l|}{ Group 6} \\
\hline Finland & daily & 2004 & Country TSO & 3'044 \\
\hline
\end{tabular}

Precipitation: Data from the European Climate Assessment and Dataset, ${ }^{17}$ which contains daily entries for 1,048 monitoring stations located in 42 countries. The period of observation varies from a few years to $>150$ years, with most series spanning several decades. To model the stochastic process underlying precipitation, I use data covering the years 19762005. The conversion of precipitation into hydroelectric power is location-specific. For example, rainfall in the Netherlands or in Denmark is largely irrelevant because these countries have very little installed hydroelectric generation capacity, whereas hydro generation constitutes a large share of total power production in Alpine and Scandinavian countries. I

\footnotetext{
${ }^{17}$ Klein Tank et al. (2007): "Daily Dataset of 20 $0^{\text {th }}$-Century Surface Air Temperature and Precipitation Series for the European Climate Assessment”, available at eca.knmi.nl, last accessed in September 2008.
} 
average station entries by country, ${ }^{18}$ and then create a weighted European average using installed hydroelectric capacity in 2006 as weights. ${ }^{19}$ Installed hydro generation is given in the last column of Table 2. Weighted precipitation in millimeters (mm) is shown in Figure 4 for a subset of the sample period. Whereas it is difficult to visually discern a pattern in the raw data (Fig. 4a), using moving 7-day-average (Fig. 4b) reveals a clear seasonality.

\footnotetext{
${ }^{18}$ For relatively flat countries such as Belgium and Luxembourg, I simply take an average of all monitoring stations. However, since hydro generation in the Alps and in Scandinavia is highly location-specific, I take an average of the subset of monitoring stations that are located in or near mountains. A full list of the selected stations is available from the author upon request.

${ }^{19}$ This data comes from UCTE (www.ucte.org) for continental Europe; from Nordpool (www.nordel.org) for Scandinavia; from the Austrian Energy Agency (www.energyagency.at/enercee/) for the Baltic States; from Harrison (2005) for the UK; and from the Electricity Supply Board (ESB, available at http://www.esb.ie/main/about_esb/power_stations_intro.jsp) for Ireland; all accessed in September 2008.
} 
Figure 3: Available daily electricity consumption, pre-2006

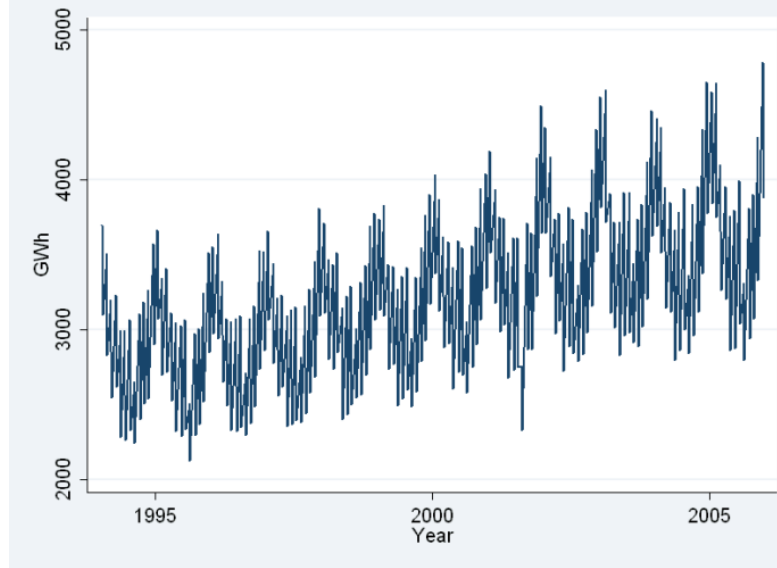

3a: Group 1 (AU, BE, FR, GR, IT, LU, NL, PT and ES)

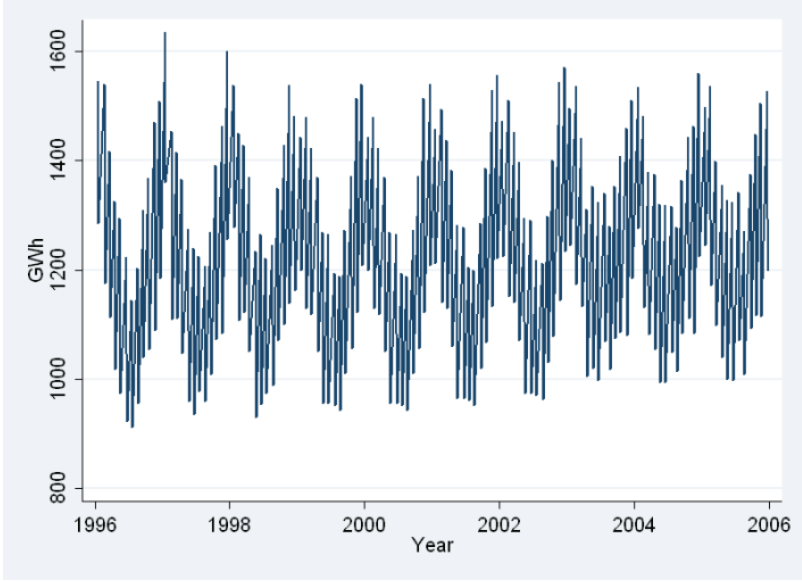

3b: Group 2 (Germany)

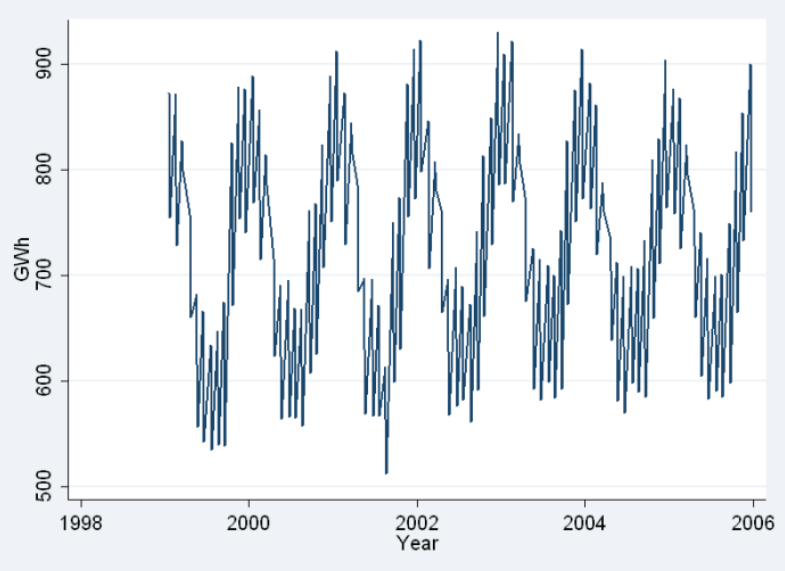

3c: Group 3 (CZ, HU, PL, SK and SK)

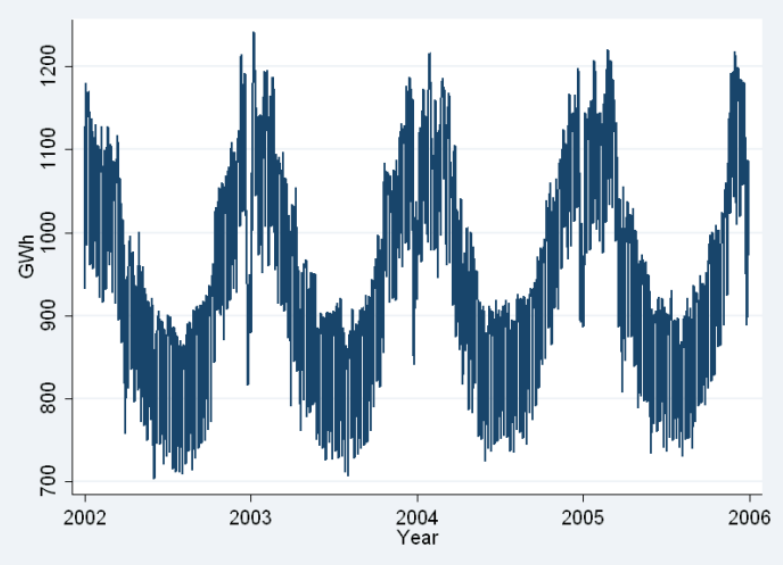

3d: Group 4 (UK and Ireland)

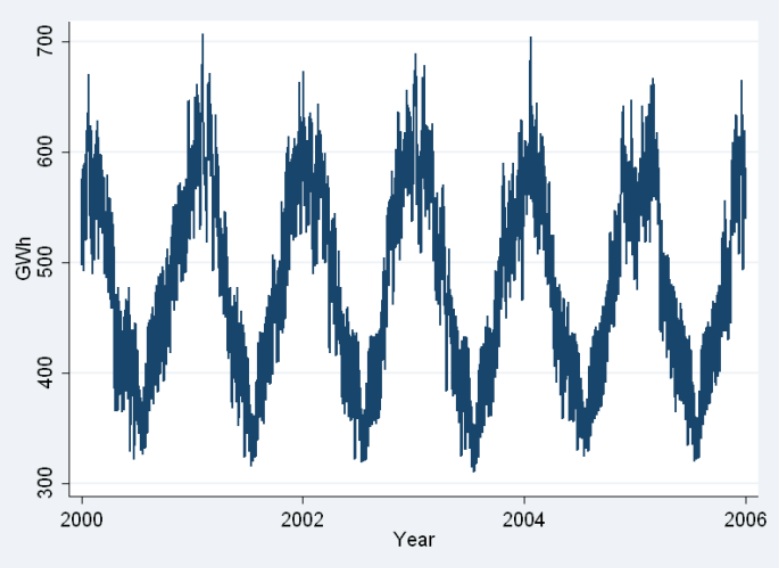

3e: Group 5 (Sweden and Denmark)

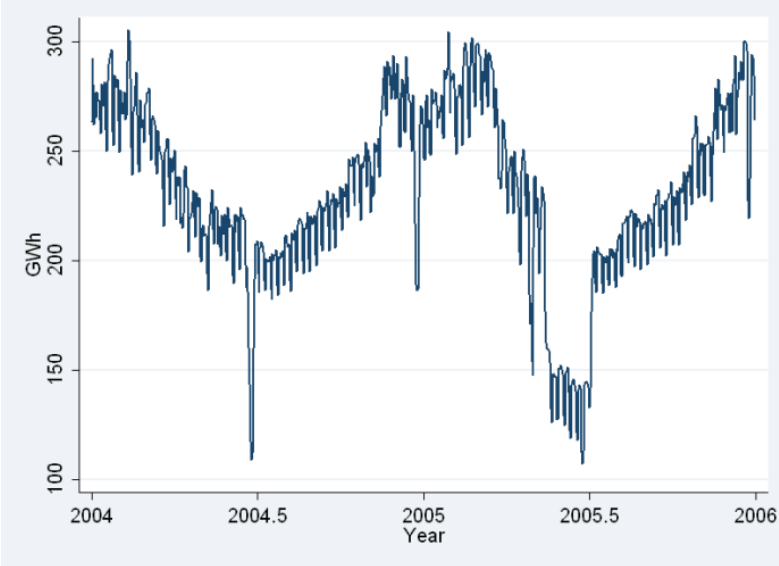

3f: Group 6 (Finland) 
Figure 4: Weighted average precipitation in the EU

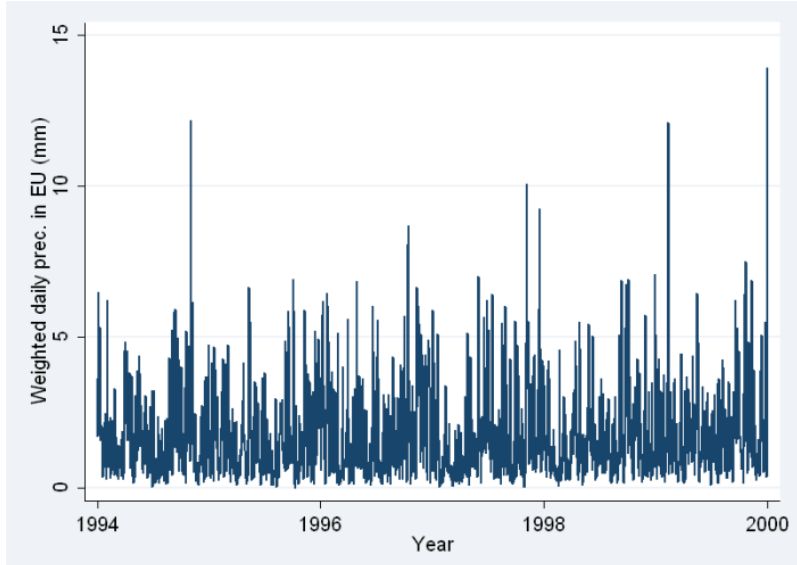

4a: Daily precipitation

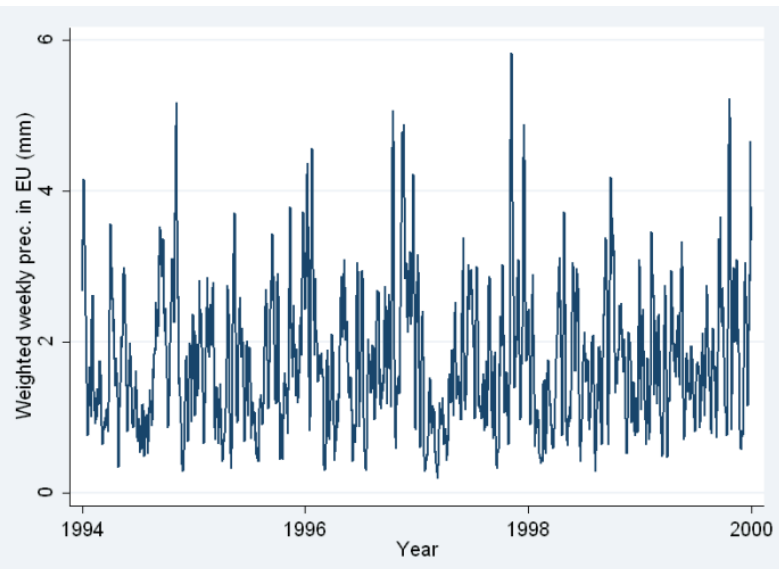

4b: Weekly moving averages

\subsection{Parameter estimation for electricity consumption and precipitation}

Using data through 2005, I estimate the parameters $\beta_{0}^{x}, \beta_{1}^{x}, \beta_{2}^{x}, \omega^{x}, D^{x}, a^{x}$ and $\sigma_{1}^{x}, \ldots, \sigma_{12}^{x}$ with a model that features an autoregressive error to account for mean-reversion and multiplicative heteroskedasticity to allow the variance to differ across months:

$$
\begin{aligned}
x_{t} & =\beta_{0}^{x}+\beta_{1}^{x} \cdot t+\alpha_{1}^{x} \cdot \sin (2 \pi t / 365)+\alpha_{2}^{x} \cdot \cos (2 \pi t / 365)+D^{x} \cdot W D_{t}+\varepsilon_{t}^{x} \\
& \varepsilon_{t}^{x}=\varphi^{x} \cdot \varepsilon_{t-1}^{x}+u_{t}^{x} \\
u_{t}^{x} & \sim N\left(0,\left(\xi_{i(t)}^{x}\right)^{2}\right) \\
& \left(\xi_{i(t)}^{x}\right)^{2}=\exp \left\{\lambda_{0}^{x}+\lambda_{1}^{x} \cdot J_{a n}+\ldots+\lambda_{11}^{x} \cdot \text { Nov }_{t}\right\} ; \quad x=c^{1}, c^{2}, \ldots, c^{6}, h
\end{aligned}
$$

The index $x$ covers six different electricity consumption series, plus the precipitation series, for which I carry out separate regressions. The parameters $\beta_{0}^{x}, \beta_{1}^{x}$ and $D^{x}$ are the same as in (14) and are estimated directly by maximum likelihood. The transformation of the sine wave plus the phase angle into a sine and cosine wave is a standard trigonometric relation and serves to linearize the equation. The parameters $\beta_{2}^{x}$ and $\omega^{x}$ can be computed using the estimates of $\alpha_{1}^{x}$ and $\alpha_{2}^{x}:{ }^{20}$

\footnotetext{
${ }^{20}$ See, for example, Beckwith et al. (1995), p. 131. The t-statistics have to be computed using the delta method.
} 


$$
\begin{aligned}
& \beta_{2}^{x}=\sqrt{\left(\alpha_{1}^{x}\right)^{2}+\left(\alpha_{2}^{x}\right)^{2}} ; \\
& \omega^{x}=\arctan \left[\alpha_{2}^{x} / \alpha_{1}^{x}\right]
\end{aligned} \quad x=c^{1}, c^{2}, \ldots, c^{6}, h
$$

For a stationary autoregressive process with one time lag, the variance is given by ${ }^{21}$

$$
\left(\sigma_{i(t)}^{x}\right)^{2}=E\left[\left(x_{t}-E\left[x_{t}\right]\right)^{2}\right]=E\left[\varepsilon_{t}^{2}\right]=\frac{\left(\xi_{i(t)}^{x}\right)^{2}}{1-\varphi_{x}}
$$

The mean-reversion parameter $a_{x}$ measures the speed at which a shock to $x_{t}$ is felt at later times. From (15), the expectation of future electricity consumption or precipitation is

$$
\begin{aligned}
E_{s}\left[x_{t}\right] & =\left[x_{s}-x_{s}^{m}\right] e^{-a_{x}(t-s)}+x_{t}^{m} \\
& =\varepsilon_{s}^{x} \cdot e^{-a_{x}(t-s)}+x_{t}^{m}
\end{aligned}
$$

The term $e^{-a_{x}(t-s)}$ is equivalent to the impulse-response function of the $\operatorname{AR}(1)$ process defined by $\chi(t, s)=\varphi^{|t-s|}$ (see e.g. Hamilton (1994) p. 53-54), which measures the impact of an exogenous shock occurring in period s on the variable in period t. Equating the two and solving yields

$$
a_{x}=-\ln \left(\varphi_{x}\right)
$$

I derived the expressions for the mean, variance and covariance in (15), (18) and (19) for aggregate electricity consumption. Having six data groups requires the following adjustment:

$$
E_{s}\left[c_{t}\right]=\sum_{j=1}^{6} E_{s}\left[c_{t}^{j}\right]
$$

\footnotetext{
${ }^{21}$ Because Series 1-3 only contain data for every $3^{\text {rd }}$ Wednesday and some weekends, and because the estimate for $\xi_{\mathrm{i}}^{\mathrm{x}}$ improves with greater frequency (Hayashi and Yoshida, 2005), I use the 2006-7 data to estimate $\varphi^{\mathrm{x}}$ and $\xi_{\mathrm{i}}^{\mathrm{x}}$ for Series 1-3. I also use 2006-7 data to estimate the correlation coefficients. For all other first-step parameters, I use pre-2006 data only. The variance and mean reversion estimates from Series 4-6 (for which such a comparison can be made) are not significantly different between pre- and post-2006 data.
} 


$$
\operatorname{Var}_{s}\left[c_{t}\right]=\sum_{j=1}^{6} \operatorname{Var}_{s}\left[c_{t}^{j}\right]+2 \sum_{j=1}^{6} \sum_{l=j+1}^{6} \operatorname{Cov}_{s}\left[c_{t}^{j}, c_{t}^{l}\right]
$$

$$
\operatorname{Cov}_{s}\left[c_{t}, c_{u}\right]=\sum_{j=1}^{6} e^{-a_{c}{ }^{*}(u-t)} * \operatorname{Var}_{s}\left[c_{t}^{j}\right]+\sum_{j=1}^{6} \sum_{l=j+1}^{6}\left(e^{-a_{c j} j^{*(u-t)}}+e^{-a_{c} c^{*}(u-t)}\right) \operatorname{Cov}_{s}\left[c_{t}^{j}, c_{t}^{l}\right]
$$

with the covariance across the individual time series given by

$$
\operatorname{Cov}_{s}\left[c_{t}^{j}, c_{t}^{l}\right]=\frac{\rho^{j l}}{a_{c^{j}}+a_{c^{\prime}}}\left\{\sum_{k=i(s)}^{i(t)-1}\left(\sigma_{k}^{c^{j}} \sigma_{k}^{c^{l}}-\sigma_{k+1}^{c^{j}} \sigma_{k+1}^{c^{l}}\right) e^{-\left(a_{c^{j}}+a_{c^{l}}\right)\left(t-t_{k+1}^{\min }\right)}+\sigma_{i(t)}^{c^{j}} \sigma_{i(t)}^{c^{l}}-e^{-\left(a_{c^{j}}+a_{c^{\prime}}\right)(t-s)} \sigma_{i(s)}^{c^{j}} \sigma_{i(s)}^{c^{\prime}}\right\}
$$

Table 3 shows the first-stage parameter estimates. The correlation coefficients in Table 4 imply that electricity consumption across the six different regions is highly correlated. Based on these estimates I compute the mean, variance and covariance terms in eqs. (10-11).

\subsection{Parameter estimation in the options formula}

I now turn to estimating the remaining parameters in the options pricing formula.

Because emissions were below the total cap for the first phase as a whole as well as for each year individually, I disregard the second line of eq. (5). Substituting (10) and (11) into (5) while using (8) and simplifying gives

$$
\begin{aligned}
& P_{t}=\left(40 e^{-r(T-t)}+P_{t}^{I I}\right) \cdot \Phi\left(\frac{\gamma A_{t}-\left(S_{0}-T k\right)}{\gamma B_{t}}\right) \\
& \text { with } \\
& \qquad \begin{aligned}
A_{t} & \equiv \sum_{k=t+1}^{T}\left(E_{t}\left[c_{k}\right]-\eta E_{t}\left[h_{k}\right]-n\right)+\sum_{k=1}^{t}\left(c_{k}-\eta h_{k}-n\right) \\
B_{t} & \equiv\left(\sum_{k=t+1}^{T} \operatorname{Var}_{t}\left[c_{k}\right]+\eta^{2} \operatorname{Var}_{t}\left[h_{k}\right]+2 \sum_{k=t+1}^{T} \sum_{u=k+1}^{T} \operatorname{Cov}_{t}\left[c_{k}, c_{u}\right]+\eta^{2} \operatorname{Cov}_{t}\left[h_{k}, h_{u}\right]\right)^{1 / 2}
\end{aligned}
\end{aligned}
$$

$A_{t}$ is the sum of past and expected future consumption of conventional electricity, whereas $B_{t}$ is the standard deviation of future conventional generation. Conditional on the firststage parameter estimates, $A_{t}$ and $B_{t}$ can be treated as exogenous daily data. 
Table 3: Parameter estimates for diffusion processes

\begin{tabular}{|c|c|c|c|c|c|c|c|}
\hline & c1 & c2 & c3 & c4 & c5 & c6 & $\mathrm{h}$ \\
\hline $\mathrm{N}$ & 168 & 144 & 108 & 1,460 & 2,190 & 730 & 10,950 \\
\hline$\beta_{0}$ & 1486.06 & 1248.56 & 654.25 & 763.47 & 569.68 & 207.54 & 23.45 \\
\hline $\mathrm{z}$ & 22.73 & 36.44 & 17.47 & 16.92 & 25.12 & 1.95 & 44.10 \\
\hline$\beta_{1}$ & 86.98 & 5.33 & 4.84 & 9.06 & -2.07 & 1.20 & -0.01 \\
\hline $\mathrm{z}$ & 32.44 & 3.92 & 3.42 & 5.57 & -2.44 & 0.33 & -0.28 \\
\hline Мo & $\mathrm{n} / \mathrm{a}$ & $\mathrm{n} / \mathrm{a}$ & $\mathrm{n} / \mathrm{a}$ & -20.84 & -3.51 & 0.66 & $\mathrm{n} / \mathrm{a}$ \\
\hline $\mathrm{z}$ & $\mathrm{n} / \mathrm{a}$ & $\mathrm{n} / \mathrm{a}$ & $\mathrm{n} / \mathrm{a}$ & -22.31 & -5.98 & 1.60 & $\mathrm{n} / \mathrm{a}$ \\
\hline Fr & $\mathrm{n} / \mathrm{a}$ & $\mathrm{n} / \mathrm{a}$ & $\mathrm{n} / \mathrm{a}$ & -20.31 & -13.98 & 1.01 & $\mathrm{n} / \mathrm{a}$ \\
\hline $\mathrm{z}$ & $\mathrm{n} / \mathrm{a}$ & $\mathrm{n} / \mathrm{a}$ & $\mathrm{n} / \mathrm{a}$ & -20.31 & -22.31 & 2.31 & $\mathrm{n} / \mathrm{a}$ \\
\hline Sa & -416.47 & -207.72 & -72.13 & -128.22 & -67.15 & -15.71 & $\mathrm{n} / \mathrm{a}$ \\
\hline $\mathrm{z}$ & 32.44 & 3.92 & 3.42 & -101.66 & -97.18 & -28.56 & $\mathrm{n} / \mathrm{a}$ \\
\hline $\mathrm{Su}$ & -750.21 & -328.49 & -128.43 & -157.64 & -72.43 & -21.45 & $\mathrm{n} / \mathrm{a}$ \\
\hline $\mathrm{z}$ & -13.80 & -26.70 & -12.23 & -133.32 & -103.87 & -43.08 & $\mathrm{n} / \mathrm{a}$ \\
\hline XNY & $\mathrm{n} / \mathrm{a}$ & $\mathrm{n} / \mathrm{a}$ & $\mathrm{n} / \mathrm{a}$ & -86.72 & -37.25 & -11.54 & $\mathrm{n} / \mathrm{a}$ \\
\hline $\mathrm{z}$ & $\mathrm{n} / \mathrm{a}$ & $\mathrm{n} / \mathrm{a}$ & $\mathrm{n} / \mathrm{a}$ & -20.08 & -12.89 & -4.85 & $\mathrm{n} / \mathrm{a}$ \\
\hline$\beta_{2}$ & 375.85 & 145.36 & 116.96 & 134.10 & 104.99 & 36.98 & 3.00 \\
\hline $\mathrm{z}$ & 18.99 & 25.19 & 32.22 & 35.09 & 41.12 & 10.91 & 7.06 \\
\hline$\omega$ & 1.33 & 1.39 & 1.41 & 1.23 & 1.34 & 1.35 & -0.40 \\
\hline $\mathrm{z}$ & 42.06 & 49.94 & 46.71 & 38.54 & 47.09 & 14.26 & -2.96 \\
\hline$\varphi^{*}$ & 0.58 & 0.39 & 0.59 & 0.84 & 0.86 & 0.91 & 0.52 \\
\hline z & 18.95 & 11.32 & 21.52 & 95.98 & 87.02 & 74.92 & 103.92 \\
\hline$a^{*}$ & 0.54 & 0.94 & 0.53 & 0.18 & 0.15 & 0.09 & 0.65 \\
\hline $\mathrm{z}$ & 10.24 & 10.68 & 11.38 & 17.15 & 13.20 & 6.94 & 68.02 \\
\hline \multicolumn{8}{|l|}{$\sigma_{i}^{*}$} \\
\hline Jan & 499.71 & 133.17 & 88.72 & 65.21 & 46.42 & 23.69 & 17.21 \\
\hline Feb & 316.67 & 94.92 & 53.10 & 45.35 & 42.27 & 23.84 & 16.15 \\
\hline Mar & 366.30 & 119.39 & 64.96 & 67.47 & 41.32 & 21.19 & 19.15 \\
\hline Apr & 453.41 & 142.96 & 79.08 & 79.32 & 51.52 & 31.36 & 14.49 \\
\hline May & 400.48 & 135.97 & 55.56 & 92.75 & 48.67 & 33.66 & 16.28 \\
\hline Jun & 387.02 & 132.80 & 59.94 & 45.64 & 46.51 & 34.84 & 16.54 \\
\hline Jul & 427.82 & 116.79 & 55.50 & 20.17 & 30.71 & 12.12 & 18.07 \\
\hline Aug & 305.51 & 97.78 & 50.71 & 69.65 & 12.10 & 7.77 & 20.91 \\
\hline Sep & 389.43 & 122.02 & 61.45 & 23.50 & 18.56 & 7.65 & 20.21 \\
\hline Oct & 387.15 & 120.30 & 64.95 & 31.66 & 27.65 & 11.17 & 22.63 \\
\hline Nov & 432.38 & 108.56 & 73.35 & 39.00 & 35.50 & 19.57 & 21.50 \\
\hline Dec & 414.69 & 163.85 & 85.40 & 96.82 & 55.91 & 42.84 & 17.68 \\
\hline
\end{tabular}

*For series 1-3, based on 2006-7 data; all other estimates based on pre-2006 data

Table 4: Correlation coefficients among different series (2006-7 data)

\begin{tabular}{llllllll}
\hline & $\mathrm{c} 1$ & $\mathrm{c} 2$ & $\mathrm{c} 3$ & $\mathrm{c} 4$ & $\mathrm{c} 5$ & $\mathrm{c} 6$ & $\mathrm{~h}$ \\
\hline $\mathrm{c} 1$ & 1.000 & & & & & & \\
$\mathrm{c} 2$ & $0.8814^{*}$ & 1.000 & & & & & \\
$\mathrm{c} 3$ & $0.9016^{*}$ & $0.8730^{*}$ & 1.000 & & & & \\
$\mathrm{c} 4$ & $0.4554^{*}$ & $0.2976^{*}$ & $0.4927^{*}$ & 1.000 & & & \\
$\mathrm{c} 5$ & $0.5170^{*}$ & $0.3897^{*}$ & $0.6032^{*}$ & $0.9231^{*}$ & 1.000 & & \\
$\mathrm{c} 6$ & $0.4588^{*}$ & $0.3672^{*}$ & $0.5573^{*}$ & $0.8496^{*}$ & $0.9418^{*}$ & 1.000 & 1.000 \\
$\mathrm{~h}$ & -0.067 & 0.014 & -0.036 & -0.038 & -0.033 & -0.020 & \\
\hline \hline
\end{tabular}

${ }^{*} \mathrm{p}<0.05$ 
Before proceeding to estimation I need to make two empirical adjustments to (25): First, because my data only covers 2006-2007 emissions and only from the power sector, I include a parameter $V$ representing 2005 emissions as well as emissions from all other sectors (in all years). Firms have expectations about this parameter, and it is evident from the April 2006 price crash that these expectations were updated after the first round of emissions verifications. As a second adjustment I therefore include an adjustment factor $V^{E V}$ multiplied by a dummy variable $D_{t}^{E V}$ taking the value of zero before, and of one after the first round of emissions verifications. This leads to the following regression specification:

$$
\begin{aligned}
P_{t}= & \left(40 e^{-r(T-t)}+P_{t}^{I I}\right) \cdot \Phi\left(\frac{\gamma A_{t}-K+D_{t}^{E V} \cdot V^{E V}}{\gamma B_{t}}\right)+\varepsilon_{t} \quad \varepsilon_{t} \sim N\left(0, \sigma_{\varepsilon}^{2}\right) \\
& K \equiv S_{0}-V-2 / 3 \cdot T k
\end{aligned}
$$

The parameter $K$ represents the number of allowances available to firms in the power sector in the years 2006-7: This number is the total cap $S_{0}$ minus emissions in 2005 and from other sectors in all years $(V)$, plus an adjustment for the difference between infra-marginal and marginal emission intensity $(2 / 3 T k){ }^{22}$ I use an interest rate r of $10 \%$ per annum (using zero and 20\% did not significantly alter the results) and estimate eq. (26) by nonlinear least squares.

As an extension I allow the standard deviation of expected future electricity consumption to differ from $B_{t}$, and further I consider the (very likely) possibility that firms updated this standard deviation after the permit price crash:

$$
P_{t}=\left(40 e^{-r(T-t)}+P_{t}^{I I}\right) * \Phi\left(\frac{\gamma A_{t}-K+D_{t}^{E V} \cdot V^{E V}}{\gamma B_{t} \cdot\left(\theta+D_{t}^{E V} \cdot \theta^{E V}\right)}\right)
$$

\footnotetext{
${ }^{22}$ If the emission intensity of inframarginal generation were the same as that of marginal generation, then $K=0$ and this adjustment drops out. The factor 2/3 generation stems from the fact that $V$ already contains total emissions for 2005.
} 
Setting $\theta=1$ and $\theta^{E V}=0$ reduces (27) to (26).

An additional empirical problem is that the parameters $K, \gamma_{t}$ and $V^{E V}$ are not individually identified. I therefore compute estimates for $\gamma_{t}$ and $V^{E V}$ conditional on $K$. Naturally, one could just as well condition on $\gamma_{t}$ or $V^{E V}$, but I argue that I have a somewhat better idea about $K$ than about $\gamma_{t}$ or $V^{E V}$. I choose a sensible range for $K$ based on the following calculation:

The total cap $S_{0}$ is 6,300 Mt (million tons) $\mathrm{CO}_{2}$, or 2,100 Mt per year (see Table 1), which I will use for expected 2005 emissions (emissions were in fact below the cap in 2005, but this was not known until the permit price crash in April 2006; in fact, this was the reason for the crash). Third-party power and CPH producers ${ }^{23}$ emit about 1,175 Mt per year, leaving $925 \mathrm{Mt}$ for all other industrial emitters in the years 2006-7 (IEA data). If firms' expectations approximately reflect these numbers, then $V \approx 2,100 \mathrm{Mt}+2 * 925=3,950 \mathrm{Mt}$.

To get an approximate estimate for $T k$, I assume that lignite plants run continuously and are never at the margin, whereas marginal generation consists of a mix of gas and hard coal generation. The emission intensity of lignite exceeds the (weighted average) emission intensity of coal and gas generation by about is about $225 \mathrm{tCO}_{2} / \mathrm{GWh}$, and electric output from lignite is about 290,000 GWh per year (IEA data). This means that $2 / 3 \cdot T k \approx 2 \cdot 225 \mathrm{t} / \mathrm{GWh} \cdot 290,000 \mathrm{GWh}$ $=130.5 \mathrm{Mt}$, which in turn implies that $K \approx 2,220 \mathrm{Mt}$. I use a range of $1,800 \mathrm{Mt} \leq K \leq 2,600 \mathrm{Mt}$ to account for the uncertainty embedded in this calculation.

The left panel in Table 5 shows the results from estimating (26) for different values of $K$. The parameter $V^{E V}$ can be interpreted as the market participants' updating of the number of permits that are available to cover emissions in the power sector. The range of 81-116 Mt

\footnotetext{
${ }^{23}$ These are generators that sell their output on the market. I assume that combined power and heat (CPH) producers optimize their power output and treat heat production as a byproduct.
} 
makes sense in the context of a market that was initially viewed to have a very stringent cap, but then turned out to have an allowance surplus of $89 \mathrm{Mt}^{24}$ The range of the emission intensity $\gamma$ of $607-876 \mathrm{tCO}_{2} / \mathrm{GWh}$ is also plausible, considering that the emission intensity of gas and coal generators is about 420 and 960 t CO$/ \mathrm{GWh}$, respectively, and that coal generators are in the majority in Europe. All estimates are statistically significant at $\mathrm{p}<0.001$.

Table 5: Parameter estimates from estimating model 1 (eq. (26)) and 2 (eq. (27); N=513

\begin{tabular}{|c|c|c|c|c|c|c|}
\hline \multirow[b]{2}{*}{$\begin{array}{l}K \\
(\mathrm{Mt})\end{array}$} & \multicolumn{2}{|c|}{ Model 1} & \multicolumn{4}{|c|}{ Model 2} \\
\hline & $\begin{array}{c}\gamma \\
\left(\mathrm{tCO}_{2} / \mathrm{GWh}\right)\end{array}$ & $\begin{array}{l}V^{E V} \\
(\mathrm{Mt})\end{array}$ & $\begin{array}{c}\gamma \\
\left(\mathrm{tCO}_{2} / \mathrm{GWh}\right)\end{array}$ & $\begin{array}{l}V^{E V} \\
(\mathrm{Mt})\end{array}$ & $\theta-1$ & $\theta^{E V}$ \\
\hline 1'800 & 606.6 & -80.6 & 606.0 & -7.8 & & \\
\hline $1^{\prime} 900$ & 640.3 & -85.0 & 639.7 & -8.3 & & \\
\hline 2'000 & 673.9 & -89.5 & 673.3 & -8.8 & & \\
\hline 2'100 & 707.6 & -94.0 & 707.0 & -9.2 & & \\
\hline 2'200 & 741.3 & -98.5 & 740.7 & -9.7 & 0.17 & -0.89 \\
\hline 2'300 & 775.0 & -103.0 & 774.3 & -10.1 & & \\
\hline $2^{\prime} 400$ & 808.7 & -107.0 & 808.0 & -10.5 & & \\
\hline 2'500 & 842.4 & -112.0 & 841.7 & -11.0 & & \\
\hline 2'600 & 876.1 & -116.0 & 875.3 & -11.4 & & \\
\hline t-value & 983.34 & -34.83 & 463.63 & -2.00 & 0.45 & -2.40 \\
\hline p-value & $<0.001$ & $<0.001$ & $<0.001$ & 0.046 & 0.653 & 0.017 \\
\hline Adj. $R^{2}$ & \multicolumn{2}{|c|}{0.9581} & \multicolumn{4}{|c|}{0.9854} \\
\hline Cox-Snell $R^{2}$ vs. Null-model & \multirow{2}{*}{\multicolumn{2}{|c|}{0.8140}} & \multicolumn{4}{|c|}{0.9450} \\
\hline model 2 vs. 1 & & & \multicolumn{4}{|c|}{0.6519} \\
\hline
\end{tabular}

The adjusted $R^{2}$ is very high, but due to the presence of the dummy variable this may not be a very meaningful measure. As an additional measure of model fit I employ the Cox-Snell generalized $R^{2}$, defined by $R_{C-S}^{2}=1-[L(0) / L(\beta)]^{2 / N}$, where $L(\beta)$ and $L(0)$ refer to the likelihood of the full model and of a model that contains only a constant and an emission verification dummy, respectively, and $N$ is the number of observations. The measure $R_{C-S}^{2}$ has an intuitive interpretation: It represents the proportion of the variation of the dependent variable

\footnotetext{
${ }^{24}$ The negative sign is due to the fact that the number of permits available to the power sector is the total number of permits in the market, minus what has been used up already, represented by $V$. A negative adjustment of $V$ implies that more permits are available for the power sector; a positive coefficient would imply the opposite.
} 
that is unexplained by the null model (Nagelkerke, 1991). Thus, Model 1 accounts for $81 \%$ of the allowance price variation that is unexplained by a model that only relies on pre- and postcrash intercepts.

The right panel of Table 5 contains the estimates from specification (27), which I call model 2. The implied emission intensity $\gamma$ is about the same as in model 1 , and the parameter estimate of $\theta=1.17$ is not significantly larger than unity, implying that $B_{t}$ correctly reflects market participants' pre-crash estimate of the standard deviation of expected future conventional electricity consumption. However, the value of $\theta^{E V}=-0.89$ implies that market participants drastically reduced their assessment of this standard deviation after the first round of emissions verification to about a quarter of $B_{t}$, coupled with a relatively small adjustment of their expectation of outstanding permits. The model fit as measured by the $R_{C-S}^{2}$ increases to 95\%. Relative to model 1 , the introduction of the two additional parameters in model 2 accounts for $65 \%$ of the remaining unexplained variation.

Since $B_{t}$ is an unbiased estimate of the standard deviation, a possible interpretation of the results of model (27) is that the new information that became available in April 2006 led market participants to under-estimate the uncertainty associated with future emissions. Naturally, such an interpretation is conditional on the model being correct, and on market participants having access to the same information as presented in this study.

Figure 5 shows the predicted price series computed using the estimates from the two specifications, along with the actual allowance price. Both predictions track the price reasonably well, although the more flexible second specification follows the EUA much closer. Importantly, both models are able to explain a stabilization of the EUA price at a level significantly above zero after the price crash. This is because although the cap was seen to be generous after the first round of emissions verifications, there remained a nonzero probability 
of higher-than-expected emissions in the future and therefore a chance that the cap would turn out to be binding in spite of the low 2005 emissions.

Figure 5: EUA price and predictions from estimating (27) and (28)

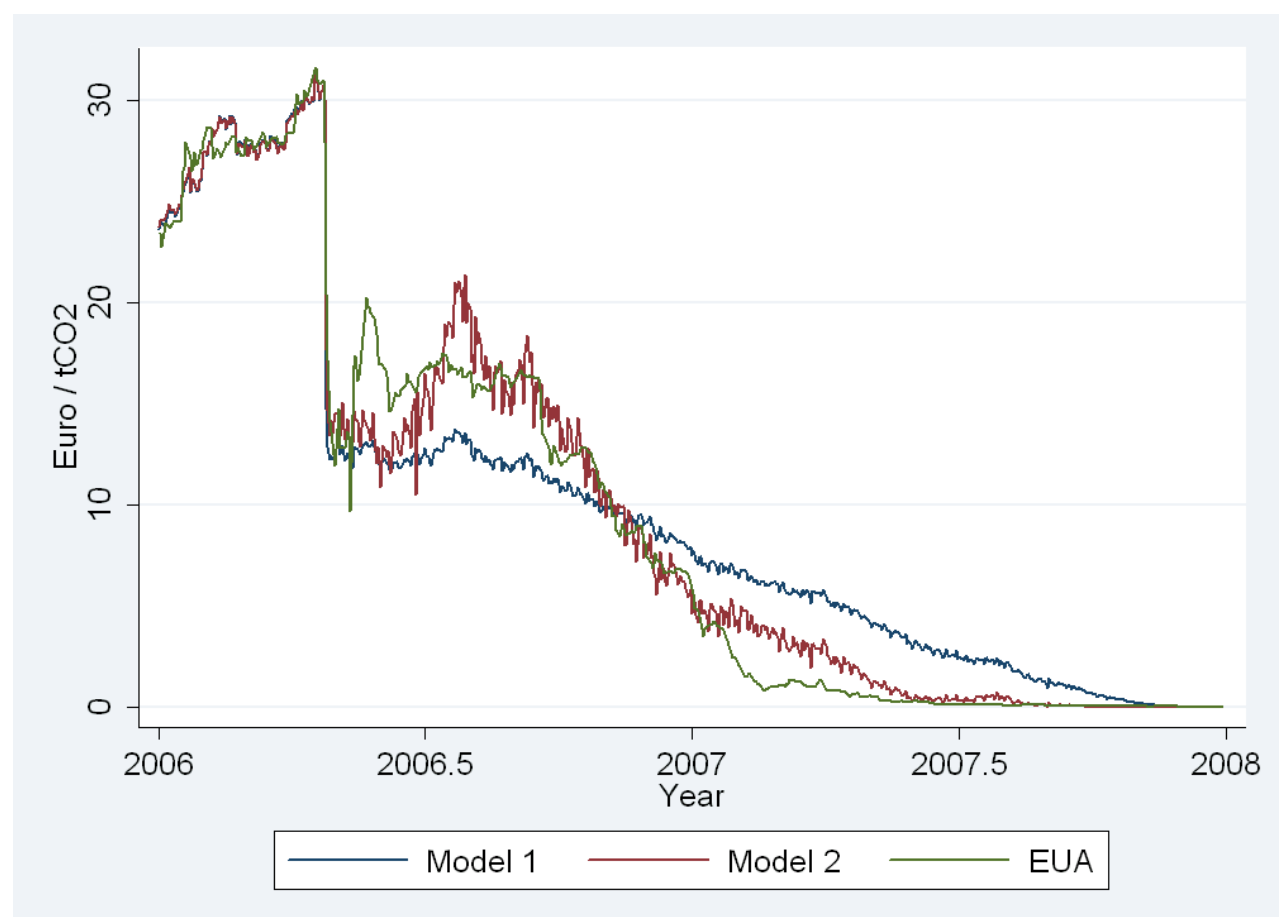

\section{Conclusions}

In this paper I derive an expression for the allowance price during phase 1 based on the assumption that emissions are stochastic and firms are unable to abate. In this case, the value of an allowance is characterized by a pricing formula for a binary option that contains the penalty of noncompliance multiplied by the probability of a binding cap.

I estimate the model using data about daily electricity consumption and precipitation. The parameter estimates of the options pricing formula are highly significant and make economic sense. The predicted allowance price series fits the observed prices well, especially when accounting for uncertainty embedded in emissions from other sectors and allowing firms' expectation of uncertainty to be updated after the first round of emissions verifications. The 
results imply that firms were hedging against the possibility of having to pay a penalty, and that uncertainty about future emissions may be a key allowance price driver.

Importantly, the model is able to explain the price stabilization after the price crash, followed by a long and steady decline towards zero, which is due to a declining (but nonzero) probability that the cap would unexpectedly turn out to be binding due to a late surge in emissions. Models based on the equality of allowance price and marginal abatement costs would only be able to explain such a movement if marginal abatement costs also expressed a steady decline towards the end of the market, a scenario for which there is no evidence in the empirical literature. This may be the reason for the generally poor performance of such models in explaining price drivers in the EU ETS.

Naturally, my results are contingent on the assumption of no abatement, which allowed me to derive a closed-form solution for the permit price and thus apply the pricing formula to market data. My model has to be understood as a polar case, whereas in reality some abatement probably did occur, especially while the allowance price remained high. If firms were partially able to control their emissions, the allowance price would presumably still exhibit some options features but at the same time incorporate drivers related to marginal abatement costs, in keeping with results reported by Carmona et al (2009).

The accumulated evidence from empirical studies suggests that abatement was not the predominant price driver during the first phase of the EU ETS. Furthermore, considering that first-phase emissions were used to determine second-phase allocation, it is entirely possible that firms did not want to abate emissions, even if they were able to do so, which empirically amounts to the same thing. In this sense, the assumption of no abatement may not be unrealistic.

Equality between permit price and marginal abatement costs is a prerequisite for efficiency in any permit market, and in this sense once would conclude that phase 1 of the EU 
ETS was not efficient. However, another goal of the first phase that was probably more important than efficiency was to prepare the market for the Kyoto period. Considering that the EUA price exhibits much less volatility in the current (second) phase, the first phase may have fulfilled its role as a pilot phase. Whether marginal abatement costs indeed drive the permit price in the current phase is, however, an open question that requires further research.

\section{Role of the funding sources}

This study was part of my dissertation at the University of Maryland (UMD), during which time I received financial support from the UMD graduate school as well as the Swiss National Foundation (SNF grant Nr. Grant Nr. PBSKP1-123496). None of these entities was involved in the actual design and implementation of this study. 


\section{References}

Alaton P, Djehiche B, Stillberger D. On modelling and pricing weather derivatives. Applied Mathematical Finance 2002;9; 1-20.

Alberola E, Chevallier J, Cheze B. Price drivers and structural breaks in European carbon prices 20052007. Energy Policy 2008;36; 787-797.

Beckwith TG, Marangoni RD, Lienhard JHV. Mechanical Measurements, Fifth Edition ed. AddisonWesley: Reading, Massachusetts; 1995.

Benz E, Trück S. Modeling the price dynamics of CO2 emission allowances. Energy Economics 2009;31; 4-15.

Boehringer C, Lange A. On the Design of Optimal Grandfathering Schemes for Emission Allowances. European Economic Review 2005;49; 2041-2055.

Bunn DW, Fezzi C, 2008. A vector error correction model of the interactions among gas, electricity and carbon prices: An application to the cases of Germany and United Kingdom, In: Gulli F (Ed), Markets for carbon and power pricing in Europe: Theoretical issues and empirical analyses. Edward Elgar Publishing; 2008. pp. 145-159.

Carmona R, Fehr M, Hinz J. Optimal Stochastic Control and Carbon Price Formation. SIAM Journal on Control and Optimization 2009;48; 2168-2190.

Chesney M, Taschini L, 2008. The Endogenous Price Dynamics of the Emission Allowances: An Application to CO2 Option Pricing. Swiss Finance Institute Research Paper Nr. 08-02, Zurich.

Cronshaw MB, Brown-Kruse J. Regulated Firms in Pollution Permit Markets with Banking. Journal of Regulatory Economics 1996;9; 179-189.

Ellerman AD, Buchner B. Over-allocation or abatement? A preliminary analysis of the EU ETS based on the emissions 2005 data. Environmental and Resource Economics 2008;41; 267-287.

Hamilton JD. Time series analysis. Princeton University Press: Princeton; 1994.

Harrison GP, 2005. Prospects for Hydro in the UK: Between a ROC and a Hard Place?, Working paper. University of Edinburgh.

Hayashi T, Yoshida N. On covariance estimation of non-synchronously observed diffusion processes. Bernoulli 2005;11; 359-379.

Hintermann B. Allowance Price Determinants in the EU ETS. Journal of Environmental Economics and Management 2010; In press.

Hull JC. Options, Futures, and Other Derivatives, Ch. 11,, 5th ed. Prentice Hall,: Upper Saddle River, NJ; 2002.

Kosobud RF, Stokes HH, Tallarico CD, Scott BL. Valuing Tradable Private Rights to Pollute the Public's Air. Review of Accounting and Finance 2005;4; 50-71.

Kruger J, Pizer W, 2004. The EU Emissions Trading Directive: Opportunities and Potential Pitfalls. Resources for the Future discussion papers, Washington, D.C., p. 62.

Leiby P, Rubin J. Intertemporal Permit Trading for the Control of Greenhouse Gas Emissions. Environmental and Resource Economics 2001;19; 229-256. 
Mansanet-Bataller M, Pardo A, Valor E. CO2 Prices, Energy and Weather. The Energy Journal 2007;28; 73-92.

Montgomery WD. Markets in Licenses and Efficient Pollution Control Programs. Journal of Economic Theory 1972;5; 395-418.

Nagelkerke NJD. A note on a general definition of the coefficient of determination. Biometrika 1991;78; 691-692.

Newell R, Pizer W, Zhang J. Managing Permit Markets to Stabilize Prices. Environmental and Resource Economics 2005;31; 133-157.

Paolella MS, Taschini L. An Econometric Analysis of Emission Trading Allowances. Journal of Banking and Finance 2008;32; 2022-2032.

PEW Center on Global Climate Change, 2005. The European Emissions Trading Scheme (EU-ETS); Insights and Opportunities, p. 20.

Rickels W, Dusch V, Keller A, Peterson S, 2007. The determinants of allowance prices in the European Emissions Trading Scheme - Can we expect an efficient allowance market 2008? . Kiel Institute for the World Economy Working Paper No. 1387, p. 28.

Rubin JD. A Model of Intertemporal Emission Trading, Banking, and Borrowing. Journal of Environmental Economics and Management 1996;31; 269-286.

Schennach SM. The Economics of Pollution Permit Banking in the Context of Title IV of the 1990 Clean Air Act Amendments. Journal of Environmental Economics and Management 2000;40; 189-210.

Seifert J, Uhrig-Homburg M, Wagner M. Dynamic Behavior of CO2 Spot Prices. Journal of Environmental Economics and Management 2008;56; 180-194.

Shreve SE. Stochastic Calculus for Finance II. Springer: New York; 2004.

Tietenberg TH. Emissions Trading: An Exercise in Reforming Pollution Policy, 1st Edition ed. Resources for the Future (RFF): Washington, D.C.; 1985.

Zhao J. Irreversible Abatement Investment under Cost Uncertainties: Tradable Emission Permits and Emissions Charges. Journal of Public Economics 2003;87; 2765-2789. 


\section{Appendix}

\section{Result 1: Variance of future emissions}

The variance of $G_{t}^{T}$ is defined by

$$
s_{t}^{2}=\operatorname{Var}_{s}\left[G_{t}^{T}\right]=\sum_{k=t+1}^{T} \operatorname{Var}_{s}\left[g_{k}\right]+2 \sum_{k=t+1}^{T} \sum_{u=k+1}^{T} \operatorname{Cov}_{s}\left[g_{k}, g_{u}\right]
$$

At time $s$, the variance $g_{t}$ and the covariance between $g_{t}$ and $g_{u}$ for $s<t<u$ are

$$
\begin{aligned}
\operatorname{Var}_{s}\left[g_{t}\right]=\operatorname{Var}_{s}[ & \left.K+\gamma_{1} c_{t}^{c}\right] \\
& =\gamma_{1}^{2} \operatorname{Var}_{s}\left[c_{t}^{c}\right] \\
& =\gamma_{1}^{2}\left(\operatorname{Var}_{s}\left[c_{t}\right]-2 \eta \operatorname{Cov}_{s}\left[c_{t}, h_{t}\right]+\eta^{2} \operatorname{Var}_{s}\left[h_{t}\right]\right)
\end{aligned}
$$

$$
\begin{aligned}
\operatorname{Cov}_{s}\left[g_{t}, g_{u}\right]=E_{s}\left[\left(g_{t}-\right.\right. & \left.\left.E_{s}\left[g_{t}\right]\right)\left(g_{u}-E_{s}\left[g_{u}\right]\right)\right] \\
= & \gamma^{2} E_{s}\left[\left\{c_{t}-E_{s}\left[c_{t}\right]-\eta\left(h_{t}-E_{s}\left[h_{t}\right]\right)\right\}\left\{c_{u}-E_{s}\left[c_{u}\right]-\eta\left(h_{u}-E_{s}\left[h_{u}\right]\right)\right\}\right] \\
= & \gamma^{2} E_{s}\left[\left(c_{t}-E_{s}\left[c_{t}\right]\right)\left(c_{u}-E_{s}\left[c_{u}\right]\right)\right]+\eta^{2} \gamma^{2} E_{s}\left[\left(h_{t}-E_{s}\left[h_{t}\right]\right)\left(h_{u}-E_{s}\left[h_{u}\right]\right)\right] \\
& -\eta \gamma^{2} E_{s}\left[\left(c_{t}-E_{s}\left[c_{t}\right]\right)\left(h_{u}-E_{s}\left[h_{u}\right]\right)\right]-\eta \gamma^{2} E_{s}\left[\left(h_{t}-E_{s}\left[h_{t}\right]\right)\left(c_{u}-E_{s}\left[c_{u}\right]\right)\right] \\
= & \gamma^{2}\left(\operatorname{Cov}_{s}\left[c_{t}, c_{u}\right]+\eta^{2} \operatorname{Cov}_{s}\left[h_{t}, h_{u}\right]-\eta \operatorname{Cov}_{s}\left[c_{t}, h_{u}\right]-\eta \operatorname{Cov}_{s}\left[h_{t}, c_{u}\right]\right)
\end{aligned}
$$

Combining (A2) and (A3) establishes the result in equation (11)

$$
\begin{aligned}
s_{t}^{2}=\gamma^{2} & \sum_{k=t+1}^{T}\left(\operatorname{Var}_{s}\left[c_{t}\right]+\eta^{2} \operatorname{Var}_{s}\left[h_{t}\right]\right) \\
& +2 \gamma^{2} \sum_{k=t+1}^{T} \sum_{u=k+1}^{T}\left(\operatorname{Cov}_{s}\left[c_{t}, c_{u}\right]+\eta^{2} \operatorname{Cov}_{s}\left[h_{t}, h_{u}\right]-\eta \operatorname{Cov}_{s}\left[c_{t}, h_{u}\right]-\eta \operatorname{Cov}_{s}\left[h_{t}, c_{u}\right]\right)
\end{aligned}
$$

\section{Result 2: Generalization of the variance for different volatilities}

Restating equation (16), the variance of $c_{t}$ and $h_{t}$ for $0 \leq s \leq t$ is

$$
\operatorname{Var}_{s}\left[x_{t}\right]=\int_{s}^{t} e^{-2 a_{x}(t-\tau)}\left(\sigma_{i(y)}^{x}\right)^{2} d y \quad x=c, h
$$


Suppose that at time s, we're in month 5 and want to calculate the variance of consumption/precipitation in month 8. Using the notation defined in the text that $t_{i(t)}^{\min }=\min \{t: i(t)=i\}$, with $i(t) \in(1, \ldots, 12)$ we have that $s<t_{6}^{\min }<t_{7}^{\min }<t_{8}^{\min }<t<t_{9}^{\min }$. I now split up the integral in (17) into four integrals with constant volatility:

$$
\operatorname{Var}_{s}\left[x_{t}\right]=\int_{s}^{t_{6}^{\min }} e^{-2 a_{x}(t-y)}\left(\sigma_{5}^{x}\right)^{2} d y+\int_{t_{6}^{\min }}^{t_{7}^{\min }} e^{-2 a_{x}(t-y)}\left(\sigma_{6}^{x}\right)^{2} d y+\int_{t_{7}^{\min }}^{t_{8}^{\min }} e^{-2 a_{x}(t-y)}\left(\sigma_{7}^{x}\right)^{2} d y+\int_{t_{8}^{\min }}^{t} e^{-2 a_{x}(t-y)}\left(\sigma_{8}^{x}\right)^{2} d y
$$

Next, I split the exponents such that they match with the new upper limits of the integrals and move the remainder (a constant) in front:

$$
\begin{aligned}
& \operatorname{Var}_{s}\left[x_{t}\right]=e^{-2 a_{x}\left(t-t_{6}^{\min }\right)^{t_{6}^{\min }}} \int_{s}^{-2 a_{x}\left(t_{6}^{\min }-y\right)}\left(\sigma_{5}^{x}\right)^{2} d y+e^{-2 a_{x}\left(t-t_{t}^{\min }\right.} \int_{t_{6}^{\min }}^{t^{\min }} e^{-2 a_{x}\left(t_{i}^{\min }-y\right)}\left(\sigma_{6}^{x}\right)^{2} d y \\
& +e^{-2 a_{x}\left(t-t_{8}^{\min }\right)} \int_{t_{7}^{\min }}^{t_{8}^{\min }} e^{-2 a_{x}\left(t_{8}^{\min }-y\right)}\left(\sigma_{7}^{x}\right)^{2} d y+\int_{t_{8}^{\min }}^{t} e^{-2 a_{x}(t-y)}\left(\sigma_{8}^{x}\right)^{2} d y
\end{aligned}
$$

Because the volatilities are constant within each integral, each of them can be solved to

$$
\begin{aligned}
\operatorname{Var}_{s}\left[x_{t}\right]= & e^{-2 a_{x}\left(t-t_{6}^{\min }\right)} * \frac{\left(\sigma_{5}^{x}\right)^{2}}{2 \rho^{x}} *\left(1-e^{-2 a_{x}\left(t_{6}^{\min }-s\right)}\right)+e^{-2 a_{x}\left(t-t_{7}^{\min }\right)} * \frac{\left(\sigma_{6}^{x}\right)^{2}}{2 \rho^{x}} *\left(1-e^{-2 a_{x}\left(t_{7}^{\min }-t_{6}^{\min }\right)}\right) \\
& +e^{-2 a_{x}\left(t-t_{8}^{\min }\right)} * \frac{\left(\sigma_{7}^{x}\right)^{2}}{2 \rho^{x}} *\left(1-e^{-2 a_{x}\left(t_{\mathrm{g}}^{\min }-t_{7}^{\min }\right)}\right)+\frac{\left(\sigma_{8}^{x}\right)^{2}}{2 \rho^{x}} *\left(1-e^{-2 a_{x}\left(t-t_{8}^{\min }\right)}\right)
\end{aligned}
$$

Multiplying out and some rearranging gives

$$
\operatorname{Var}_{s}\left[x_{t}\right]=\frac{1}{2 a_{x}}\left\{\begin{array}{l}
\left(\left(\sigma_{5}^{x}\right)^{2}-\left(\sigma_{6}^{x}\right)^{2}\right) e^{-2 a_{x}\left(t-t_{6}^{\min }\right)}+\left(\left(\sigma_{6}^{x}\right)^{2}-\left(\sigma_{7}^{x}\right)^{2}\right) e^{-2 a_{x}\left(t-t_{7}^{\min }\right)} \\
+\left(\left(\sigma_{7}^{x}\right)^{2}-\left(\sigma_{8}^{x}\right)^{2}\right) e^{-2 a_{x}\left(t-t_{8}^{\min }\right)}+\left(\sigma_{8}^{x}\right)^{2}-\left(\sigma_{5}^{x}\right)^{2} e^{-2 a_{x}(t-s)}
\end{array}\right\}
$$

which can be generalized to

$$
\operatorname{Var}_{s}\left[x_{t}\right]=\frac{1}{2 a_{x}}\left\{\sum_{k=i(s)}^{i(t)-1}\left(\left(\sigma_{k}^{x}\right)^{2}-\left(\sigma_{k+1}^{x}\right)^{2}\right) e^{-2 a_{x}\left(t-t_{i(k+1)}^{\min }\right)}+\left(\sigma_{i(t)}^{x}\right)^{2}-e^{-2 a_{x}(t-s)}\left(\sigma_{i(s)}^{x}\right)^{2}\right\}
$$




\section{Result 3: Covariance of $x$ on two different days}

The covariance between $x_{t}$ and $x_{u}$, for $x=c, h$ and $s \leq t \leq u$ is given by

$$
\begin{aligned}
\operatorname{Cov}_{s}\left[x_{t}, x_{u}\right] & =E_{s}\left[\left(x_{t}-E_{s}\left[x_{t}\right]\right)\left(x_{u}-E_{s}\left[x_{u}\right]\right)\right] \\
& =E_{s}\left[\int_{s}^{t} e^{-\rho^{x}(t-\tau)} \sigma_{x}[i(\tau)] d W_{\tau} * \int_{s}^{u} e^{-\rho^{x}(u-\tau)} \sigma_{x}[i(\tau)] d W_{\tau}\right]
\end{aligned}
$$

I split up the second integral into two parts and pull out the constant term:

$$
\operatorname{Cov}_{s}\left[x_{t}, x_{u}\right]=E_{s}\left[\int_{s}^{t} e^{-\rho^{x}(t-\tau)} \sigma_{x}[i(\tau)] d W_{\tau} *\left(e^{-\rho^{x}(u-t)} \int_{s}^{t} e^{-\rho^{x}(t-\tau)} \sigma_{x}[i(\tau)] d W_{\tau}+\int_{t}^{u} e^{-\rho^{x}(u-\tau)} \sigma_{x}[i(\tau)] d W_{\tau}\right)\right]
$$

Multiplying out gives

$$
\begin{aligned}
\operatorname{Cov}_{s}\left[x_{t}, x_{u}\right]=e^{-\rho^{x}(u-t)} E_{s}\left[\int_{s}^{t} e^{-\rho^{x}(t-\tau)} \sigma_{x}[i(\tau)] d W_{\tau} * \int_{s}^{t} e^{-\rho^{x}(t-\tau)} \sigma_{x}[i(\tau)] d W_{\tau}\right] \\
+E_{s}\left[\int_{s}^{t} e^{-\rho^{x}(t-\tau)} \sigma_{x}[i(\tau)] d W_{\tau} * \int_{t}^{u} e^{-\rho^{x}(u-\tau)} \sigma_{x}[i(\tau)] d W_{\tau}\right]
\end{aligned}
$$

The second term is the expectation of the product of two stochastic processes occurring during non-overlapping time periods. Because a Wiener process is i.i.d., this term drops out. Using the fact that $(d W)^{2}=d t$ establishes the result:

$$
\begin{aligned}
\operatorname{Cov}_{s}\left[x_{t}, x_{u}\right]=e^{-\rho^{x}(u-t)} E_{s} & {\left[\int_{s}^{t} e^{-\rho^{x}(t-\tau)} \sigma_{x}[i(\tau)] d W_{\tau} * \int_{s}^{t} e^{-\rho^{x}(t-\tau)} \sigma_{x}[i(\tau)] d W_{\tau}\right] } \\
& =e^{-\rho^{x}(u-t)} E_{s}\left[\int_{s}^{t} e^{-2 \rho^{x}(t-\tau)} \sigma_{x}^{2}[i(\tau)]\left(d W_{\tau}\right)^{2}\right] \\
& =e^{-\rho^{x}(u-t)} * \operatorname{Var}_{s}\left[x_{t}\right]
\end{aligned}
$$

